\title{
YAP Mediates Hair Cell Regeneration in Balance Organs of Chickens, But LATS Kinases Suppress Its Activity in Mice
}

\author{
${ }^{\circledR}$ Mark A. Rudolf, ${ }^{1}{ }^{\circledR}$ Anna Andreeva, ${ }^{2}{ }^{\circledR}$ Mikolaj M. Kozlowski, ${ }^{1}$ Christina E. Kim, ${ }^{1}$ Bailey A. Moskowitz, ${ }^{1}$ \\ ${ }^{(1)}$ Alejandro Anaya-Rocha, ${ }^{3}{ }^{\circledR}$ Matthew W. Kelley, ${ }^{3}$ and ${ }^{\circledR}$ Jeffrey T. Corwin ${ }^{1,4}$ \\ ${ }^{1}$ Department of Neuroscience, University of Virginia School of Medicine, Charlottesville, Virginia 22908, ${ }^{2}$ School of Sciences and Humanities, \\ Nazarbayev University, Nursultan 010000, Republic of Kazakhstan, ${ }^{3}$ Laboratory of Cochlear Development, National Institute on Deafness and Other \\ Communication Disorders, National Institutes of Health, Bethesda, Maryland 20892, and ${ }^{4}$ Department of Cell Biology, University of Virginia School \\ of Medicine, Charlottesville, Virginia 22908
}

Loss of sensory hair cells causes permanent hearing and balance deficits in humans and other mammals, but for nonmammals such deficits are temporary. Nonmammals recover hearing and balance sensitivity after supporting cells proliferate and differentiate into replacement hair cells. Evidence of mechanical differences between those sensory epithelia and their supporting cells prompted us to investigate whether the capacity to activate YAP, an effector in the mechanosensitive Hippo pathway, correlates with regenerative capacity in acceleration-sensing utricles of chickens and mice of both sexes. After hair cell ablation, YAP accumulated in supporting cell nuclei in chicken utricles and promoted regenerative proliferation, but YAP remained cytoplasmic and little proliferation occurred in mouse utricles. YAP localization in supporting cells was also more sensitive to shape change and inhibition of MST1/2 in chicken utricles than in mouse utricles. Genetic manipulations showed that in vivo expression of the YAP-S127A variant caused robust proliferation of neonatal mouse supporting cells, which produced progeny that expressed hair cell markers, but proliferative responses declined postnatally. Expression of YAP-5SA, which more effectively evades inhibitory phosphorylation, resulted in TEAD-dependent proliferation of striolar supporting cells, even in adult utricles. Conditional deletion of LATS1/2 kinases abolished the inhibitory phosphorylation of endogenous YAP and led to striolar proliferation in adult mouse utricles. The findings suggest that damage overcomes inhibitory Hippo signaling and facilitates regenerative proliferation in nonmammalian utricles, whereas constitutive LATS1/2 kinase activity suppresses YAP-TEAD signaling in mammalian utricles and contributes to maintaining the proliferative quiescence that appears to underlie the permanence of sensory deficits.

Key words: hair cell; Hippo; LATS; regeneration; utricle; YAP

Significance Statement

Loud sounds, ototoxic drugs, infections, and aging kill sensory hair cells in the ear, causing irreversible hearing loss and balance deficits for millions. In nonmammals, damage evokes shape changes in supporting cells, which can divide and regenerate hair cells. Such shape changes are limited in mammalian ears, where supporting cells develop E-cadherin-rich apical junctions reinforced by robust F-actin bands, and the cells fail to divide. Here, we find that damage readily activates YAP in supporting cells within balance epithelia of chickens, but not mice. Deleting LATS kinases or expressing YAP variants that evade LATSmediated inhibitory phosphorylation induces proliferation in supporting cells of adult mice. YAP signaling eventually may be harnessed to overcome proliferative quiescence that limits regeneration in mammalian ears.

\section{Introduction}

Hearing loss affects over 400 million people worldwide, and balance disorders afflict millions more (Agrawal et al., 2009; World Health Organization, 2018). The loss of sensory hair cells (HCs)

Received Feb. 7, 2020; revised Apr. 7, 2020; accepted Apr. 13, 2020

Author contributions: M.A.R., A. A., M.W.K., and J.T.C. designed research; M.A.R., A. A., M.M.K., C.E.K., and A.A-R performed research; M.A.R., A. A., and B.A.M. analyzed data; M.A.R. wrote the first draft of the paper; M.A.R., A. A., M.M.K., M.W.K., and J.T.C. edited the paper.

The authors declare no competing financial interests. in the inner ear is a major and permanent cause of these impairments because lost HCs are not effectively replaced in humans and other mammals (Forge et al., 1993; Nadol, 1993; Warchol et

This work was supported by National Institute on Deafness and Other Communication Disorders/National Institutes of Health R01 DC000200 to J.T.C., National Institute on Deafness and Other Communication Disorders/National Institutes of Health F30 DC016806 to M.A.R., and National Institute on Deafness and Other Communication Disorders/National Institutes of Health ZIA DC000059 to M.W.K. We thank Dr. George Hashisaki and colleagues (University of Virginia Department of Otolaryngology-Head and Neck Surgery) for providing a human tissue sample; Dr. Jung-Bum Shin, and Dr. Xiaowei Lu for helpful discussions; and Lorela Çiraku and Robin Singleton for technical help. 
al., 1993; Golub et al., 2012; Mizutari et al., 2013). In contrast, birds, fish, and amphibians efficiently replace HCs after damage and recover sensory function (Corwin and Cotanche, 1988; Ryals and Rubel, 1988; Jones and Corwin, 1996; Smolders, 1999; Harris et al., 2003; Smith et al., 2006; Lush and Piotrowski, 2014). In those nonmammals, neighboring supporting cells (SCs) either generate progeny that replace HCs, or convert directly into HCs (Balak et al., 1990; Adler and Raphael, 1996; Baird et al., 1996). However, the capacity for mammalian SCs to divide and replace HCs declines sharply after birth, for reasons that are yet unclear (Burns et al., 2012a; Cox et al., 2014). Efforts to enhance the regenerative response of mammalian SCs have included treatments with growth factors, inhibition of Notch signaling, and stimulation of canonical Wnt signaling ( $\mathrm{Gu}$ et al., 2007; Wang et al., 2015a; You et al., 2018). These manipulations show promise in neonatal mice, but their efficacy diminishes as mammals mature and SCs transition to a more persistent state of quiescence (Gu et al., 2007; Collado et al., 2011b; Maass et al., 2015; Atkinson et al., 2018; Samarajeewa et al., 2018). There remains a need to understand the mechanisms that maintain mammalian SCs in this quiescent state.

A possible explanation arose from studies of the utricle, a type of balance organ. In cultured sheets of utricular epithelia, SCs from immature mice rapidly spread and proliferate, but the ability to spread and proliferate declines abruptly with age (Davies et al., 2007; Meyers and Corwin, 2007; Lu and Corwin, 2008). At the same time, mammalian SCs develop reinforced apical junctions with high levels of E-cadherin and exceptionally thick circumferential F-actin bands (Burns et al., 2008, 2013; Collado et al., 2011b; Luo et al., 2018). In contrast, SCs from chickens express little Ecadherin, have thin F-actin bands at their apical junctions, and freely spread and proliferate throughout life (Burns et al., 2008, 2013). The implications led us to investigate the Hippo pathway and its effector, Yes-associated protein (YAP), which integrate mechanical and biochemical input to control proliferation (Irvine and Shraiman, 2017; Totaro et al., 2018).

In the canonical Hippo pathway, the kinase cascade of MST1/ 2 and LATS1/2 phosphorylates YAP, leading to its cytoplasmic sequestration and degradation (Dong et al., 2007; Zhao et al., $2007,2010)$. In the absence of such inhibitory signaling, YAP can accumulate in nuclei where it promotes proliferation with TEAD transcription factors (Vassilev et al., 2001; Zhao et al., 2007). YAP-TEAD transcriptional activity declines in response to increases in cell density during utricular development, contributing to the initial arrest of growth (Gnedeva et al., 2017), but the role of MST1/2 and LATS1/2 in the inner ear has not yet been studied. We hypothesized that damage would readily reactivate YAP-TEAD signaling within SCs in the regenerative ears of nonmammals, but would not in the ears of mammals.

Here, we report that, in the chicken utricle, MST1/2-dependent Hippo signaling sequestered YAP in the cytoplasm of SCs, and that $\mathrm{HC}$ loss caused YAP to accumulate in nuclei and promote regenerative proliferation. In SCs of the murine utricle, YAP remained cytoplasmic after HC loss. There, proliferative quiescence was overcome by expression of phosphorylation-insensitive variants of YAP or conditional deletion of LATS1/2, even in utricles from adult mice. The findings provide a novel mechanistic basis to account for differences in the regenerative replacement of

Correspondence should be addressed to Jeffrey T. Corwin at corwin@virginia.edu.

https://doi.org/10.1523/JNEUROSCI.0306-20.2020

Copyright $\odot 2020$ the authors
HCs between mammals and nonmammals and demonstrate, for the first time, that YAP-TEAD signaling can be harnessed to promote the proliferation of SCs in the mammalian inner ear.

\section{Materials and Methods}

Animals

All experiments and procedures were approved by the University of Virginia Animal Care and Use Committee (protocol \#18350718). Swiss Webster mice were obtained from Charles River Laboratories. Animals of either sex were used for all experiments. In some experiments, 5-ethynyl-2deoxyuridine (EdU, Cayman Chemical) was injected at $50 \mu \mathrm{g} / \mathrm{g}$ subcutaneously to trace the incidence of S-phase entry. Doxycycline hyclate (Sigma Millipore) was supplied to the mice in drinking water at $2 \mathrm{mg} / \mathrm{ml}$, and/or via intraperitoneal injection at $100 \mu \mathrm{g} / \mathrm{g}$ body weight dissolved in saline.

Sox $10^{r t T A /+}$ mice were generated by the laboratory of Michael Wegner (Ludwig et al., 2004) and contain a knock-in allele of the reverse tetracycline controlled transactivator (rtTA) in the Sox10 locus. YapS127A mice harbor a doxycycline-dependent human YAP1 transgene with a serine to alanine mutation at Serine 127 in the Colla1 locus (Camargo et al., 2007). Mice were maintained on a mixed background. Lats $f^{\text {floxfflox }}$ (stock \#024941) and Lats $2^{\text {flox/flox }}$ (stock \#025428) mice were obtained from The Jackson Laboratory and originally developed by the lab of Randy L. Johnson (Heallen et al., 2013). Plp-CreER mice were obtained from The Jackson Laboratory (stock \#005975) and originally developed by the lab of Brian Popko (Doerflinger et al., 2003). Yap ${ }^{\text {flox/flox }} ; \mathrm{Taz}^{\text {flox/flox }}$ mice were generated and kindly provided by the lab of Eric Olson (Xin et al., 2011, 2013).

Fertilized White Leghorn (W-36) eggs were obtained from Hy-Line and incubated at $37^{\circ} \mathrm{C}$ in a humidified chamber with rocking until E18, after which eggs were incubated without rocking. Utricles were harvested from chicks of either sex between posthatch days $0-4$.

\section{Utricle dissection and culture}

Labyrinths were dissected from temporal bones in ice-cold PBS with $\mathrm{Ca}^{2+} / \mathrm{Mg}^{2+}$ (Invitrogen), and isolated utricles were transferred to HEPES-buffered DMEM/F-12 (Invitrogen) for fine dissection. The utricular roof, otoconia, and nerve were mechanically removed under aseptic conditions. The dissected organs contained the entire sensory epithelium, a small portion of the surrounding nonsensory epithelium, and the underlying connective tissue matrix. For organ culture, dissected utricles were adhered to glass-bottom dishes (Mat-Tek) coated with $0.5 \mu \mathrm{l}$ of dried Cell-Tak (BD Biosciences). Utricles were incubated at $37^{\circ} \mathrm{C}$ with $5 \% \mathrm{CO}_{2}$ and cultured in HEPES-buffered DMEM/F12 supplemented with $1 \%$ FBS (Invitrogen) and $10 \mu \mathrm{g} / \mathrm{ml}$ ciprofloxacin (Bayer). In some experiments, 5-bromo-2'-deoxyuridine (BrdU, Sigma) was supplemented at $5 \mu \mathrm{g} / \mathrm{ml}$ or EdU (Cayman Chemical) was supplemented at $2.5 \mu \mathrm{g} / \mathrm{ml}$ to trace cells that entered S-phase. Streptomycin sulfate was obtained from Sigma-Aldrich (\#S9137) and dissolved in DMEM/F-12. CA3 was obtained from Selleck Chemicals (\#S8661) and reconstituted in DMSO. Leptomycin B was obtained from Calbiochem predissolved in ethanol (\#431050) and used at $40 \mathrm{ng} / \mathrm{ml}$. XMU-MP-1 (\#22083) was obtained from Cayman Chemical, reconstituted in DMSO, and used at $3 \mu \mathrm{M}$.

\section{Adenoviral transduction}

Type 5 adenoviral constructs were generated by Vector Biolabs. Viruses for transduction of WT mouse YAP (\#ADV-276436), mCherry (\#1767), and mCherry-T2A-Cre (\#1773) were purchased from stock inventory, and other constructs were custom-made from the following plasmids that were obtained from Addgene: pCMV-Flag-YAP-5SA (\#27371) and pCMV-Flag-YAP-5SA/S94A (\#33103). Cultured utricles were rinsed 3 times with warm DMEM/F12 + HEPES without serum, and then incubated with adenovirus at a final concentration of $1 \times 10^{8} \mathrm{PFU} / \mathrm{ml}$ for $6 \mathrm{~h}$. Vector Biolabs titers its viruses using the plaque formation assay. The transduction rate was assessed by counting $\mathrm{mCherry}^{+}$cells in highmagnification confocal images.

Immunohistochemistry and imaging

Utricles were fixed in 4\% PFA (Electron Microscopy Sciences) in PBS for $1 \mathrm{~h}$ at room temperature or in Glyofixx (Shandon) at $4^{\circ} \mathrm{C}$ overnight. 
Then utricles were rinsed 3 times in PBS with $0.1 \%$ Triton X-100 (PBST) and blocked with 10\% normal goat serum (Vector Laboratories) for $2 \mathrm{~h}$ at room temperature. Primary antibodies were incubated at $4^{\circ} \mathrm{C}$ overnight in PBST supplemented with $2 \%$ normal goat serum. Utricles were then rinsed 3 times in PBST and incubated with AlexaFluorconjugated goat secondary antibodies for $2 \mathrm{~h}$ at room temperature in PBST with 2\% normal goat serum. Utricles were then rinsed 3 times in PBST, mounted in Prolong Diamond, and imaged on an LSM 880 confocal microscope (Carl Zeiss). For BrdU-labeled specimens, utricles were treated with DNase I from bovine pancreas (50 Kunitz/ml, Sigma Millipore) for $1 \mathrm{~h}$ at $37^{\circ} \mathrm{C}$ following permeabilization and prior to blocking and incubation with primary antibodies.

Mouse anti-E-cadherin (1:200, clone 36) and mouse anti-BrdU (1:20, B44) were obtained from BD Biosciences. Mouse anti-YAP (1:50, 101199) was obtained from Santa Cruz Biotechnology, and was validated in Yap ${ }^{f l o x / f l o x} ;$ Taz $^{\text {floxfflox }}$;PlpCreER mice. Mouse anti-Spectrin (1:50, MAB1622) was obtained from Millipore. Rabbit anti-Sox2 (1:200, D9B8N), rabbit antiphospho-YAP (Ser127) (1:100, 4911), and rabbit anti-TEAD1 (1:200, D9X2L) were obtained from Cell Signaling Technology. Rabbit anti-Ki67 (1:200, RM9106S0) was obtained from Thermo Fisher Scientific. Rabbit anti- $\beta$-tectorin (Tectb) (1:1000) was a generous gift from Guy Richardson. Rabbit anti-Pv3 (1:400) was a generous gift from Stefan Heller. Rabbit antimyosin VI (1:200, 25-6791) and rabbit anti-myosin VIIa (1:200, 25-6790) were obtained from Proteus. Mouse anti-myosin VIIa (1:100, 138-1) was obtained from the Developmental Studies Hybridoma Bank. Rabbit anti-ZO-1 (1:200, 61-7300) was obtained from Zymed. AlexaFluor-conjugated secondary antibodies (1:500) and AlexaFluor-conjugated phalloidin (1:200) were obtained from Thermo Fisher Scientific. EdU was visualized with the Click-it AlexaFluor Imaging Kit (Thermo Fisher Scientific) according to the manufacturer's instructions.

\section{Quantification of S-phase entry}

In experiments with chicken utricles, S-phase entry was measured by tabulating the number of $\mathrm{EdU}^{+}$cells in three $225 \times 225 \mu \mathrm{m}$ confocal images acquired at high magnification from the medial extrastriolar region. The incidence of S-phase entry in vivo in Yap-S127A;Sox10 $0^{r T A /+}$ mice was measured by counting the number of $\mathrm{EdU}^{+}$cells within confocal $z$ stacks obtained with $20 \times$ magnification. The average number of $\mathrm{EdU}^{+}$cells across five standardized $100 \times 100 \mu \mathrm{m}$ regions were combined into a single value that was considered an independent replicate for statistical purposes. Two $100 \times 100 \mu \mathrm{m}$ regions were located in the lateral aspect of the macula (corresponding to the lateral extrastriola), one region was located in the center of the macula (roughly corresponding to the striolar region), and two regions were located in the medical aspect of the macula (corresponding to the medial extrastriolar region). Only one utricle per mouse was analyzed to quantify S-phase entry across genotypes in those in vivo experiments. In other experiments, we counted all cells in the utricular macula that incorporated BrdU or EdU using confocal $z$ stacks obtained at $20 \times$ magnification.

\section{Quantification of YAP nuclear:cytoplasmic intensity ratio}

Images were analyzed with FIJI (Schindelin et al., 2012). YAP nuclear: cytoplasmic intensity ratios ( $\mathrm{N}: \mathrm{C}$ ratios) were calculated from high-magnification confocal images of the SC nuclear layer using a custom FIJI script available at https://github.com/utricle/YAP-NC-Ratio. Utricles were immunostained for YAP, phalloidin, and Myo7a or Sox2. In samples stained for Myo7a, pixels that exceeded an Otsu threshold for Myo7a were considered HCs and excluded from the analysis. On each individual image, the cytoplasmic region was defined by pixels which exceeded an Otsu threshold for phalloidin. The nuclear region was defined by pixels which exceeded an Otsu threshold for Sox2, or alternatively by using the inverse of the cytoplasm region. The average YAP intensity in the cytoplasmic region divided by the nuclear region was computed for each individual image. Three to five locations were imaged per utricle. In mouse utricles, at least one lateral, one central, and one medial image was acquired. The lateral region corresponds to the extrastriolar cells lateral to the line of polarity reversal, the central region corresponds to striolar cells just medial to the line of polarity reversal, and the medial region corresponds to extrastriolar cells adjacent to the medial boundary of the macula. In chicken utricles, all images were acquired within the large medial extrastriolar region. All YAP N:C ratios from a given utricle were averaged together to form a single ratio for each utricle, which was considered an independent replicate for statistical analysis.

In P30 mouse utricles that were transduced with adenovirus, the YAP N:C ratios were collected by hand. Cells that expressed the mCherry reporter were identified in high-magnification confocal images of the SC nuclear layer, and ROIs were drawn in the nucleus (excluding nucleoli) and in the thin surrounding cytoplasmic space. The number of cells analyzed per utricle ranged from 15 to 96 , with at least 128 total cells analyzed per experimental group. Values from the same utricle were averaged and considered a single independent replicate for statistical analysis.

\section{Micropunch lesions}

Micropunches were fabricated as previously described (Meyers and Corwin, 2007). Blunt 29-gauge hypodermic needles with internal diameter of $180 \mu \mathrm{m}$ (catalog \#91029, Hamilton) were electrolytically etched in a solution of $34 \%$ sulfuric acid and $42 \%$ phosphoric acid at $1.5 \mathrm{~V}, 500$ $\mathrm{mA}$, and rough edges were removed with polishing paper (catalog \#337308, Rio Grande), creating a sharp, circular edge. After utricles from P2 chickens or P1 mice were cultured for $24 \mathrm{~h}$, the micropunch was pressed into the center of the macula. The epithelium within the lesion site was excised with a sharpened tungsten filament (catalog \#716200, A-M Systems), leaving the underlying stroma intact. Utricles were cultured for an additional $48 \mathrm{~h}$ with or without $10 \mu \mathrm{M}$ EdU prior to fixation.

Confocal image stacks were acquired within the lesion site and an undamaged region at the periphery of the macula. Because the diameter of the micropunch exceeds the mediolateral span of the striola $(\sim 100$ $\mu \mathrm{m})$, lesion sites included both striolar and extrastriolar regions. In each utricle, SC apical domains in the lesion site were visualized with phalloidin staining and measured using hand-drawn ROIs in FIJI. The corresponding nuclei were identified in the $z$ stack for measurement of the YAP N:C ratio. For each SC, one ROI was drawn in the nucleus, avoiding nucleoli, and one ROI was drawn in the perinuclear region to serve as the cytoplasm ROI. The average intensity of YAP immunostaining in the nuclear ROI was divided by that in the cytoplasm ROI to calculate the YAP N:C ratio. In this manner, the 30 SCs at the center of each lesion site were analyzed in each of four utricles (120 SCs total). The regression analysis of SC area and YAP N:C ratio was performed using GraphPad Prism 8 software. To compare the YAP N:C ratio in chicken and mouse SCs, SCs were separated based on area into four different groups $\left(<50 \mu \mathrm{m}^{2}, 50-75 \mu \mathrm{m}^{2}, 75-100 \mu \mathrm{m}^{2}\right.$, and $\left.>100 \mu \mathrm{m}^{2}\right)$, with $19-58$ SCs of each species per group. A two-way ANOVA was used to compare the YAP N:C ratio across species and area.

In the undamaged region outside of the lesion site, the area of $30 \mathrm{SC}$ apical domains per utricle were measured as described above. The YAP $\mathrm{N}: \mathrm{C}$ ratio in the undamaged region was calculated from a confocal image slice of the SC nuclear layer using the custom FIJI script described above.

Quantification of macular area and cell density

Yap-S127A ${ }^{+/-}$;Sox $10^{r \text { tTA/+ }}$ mice and littermate controls (WT, Yap$S 127 A^{+/-}$, and Sox $10^{r t T A /+}$ ) received an intraperitoneal injection of doxycycline at P1. Utricles were harvested and fixed on P5 for immunostaining for rabbit anti-ZO-1 and mouse IgG1 anti-Myo7a. After mounting as whole mounts, utricles were imaged on a LSM 880 confocal microscope (Carl Zeiss). Macular areas were measured from maximum intensity projections of Myo7a imaged with a $20 \times$ objective. Higher-magnification images were obtained from the lateral, central, and medial region of each utricle, and the total number of SCs (Myo7a- cell apices) and HCs (Myo7a ${ }^{+}$cell apices) were counted. The lateral image corresponded to the lateral extrastriola, the central image roughly corresponded to the striola, and the medial image corresponded to the medial extrastriola. The totals from each region were averaged to produce an overall SC density, HC density, and total cell density for each utricle (normalized to $10,000 \mu \mathrm{m}^{2}$ ), which was considered an independent statistical replicate. Only one utricle was analyzed per mouse.

\section{Quantification of E-cadherin immunoreactivity}

Yap-S127A ${ }^{+/-}$; Sox $10^{\text {rtTA/+ }}$ mice and littermate controls (WT, Yap$S 127 A^{+/-}$, and Sox $10^{r t T A /+}$ ) received an intraperitoneal injection of 
Table 1. Primers for qRT-PCR

\begin{tabular}{|c|c|c|c|c|}
\hline$\overline{\text { Gene }}$ & Species & Direction & Sequence & $\overline{\text { Amplicon size (bp) }}$ \\
\hline \multirow[t]{2}{*}{ Ctgf } & \multirow[t]{2}{*}{ Mouse } & Forward & ACTATGATGCGAGCCAACTG & \multirow[t]{2}{*}{117} \\
\hline & & Reverse & CTCCAGTCTGCAGAAGGTATTG & \\
\hline Cyr61 & Mouse & Forward & CCAGTGTACAGCAGCCTAAA & 92 \\
\hline \multirow[t]{2}{*}{ Ankrd1 } & \multirow[t]{2}{*}{ Mouse } & Forward & CGACGTCTGCGATGAGTATAAA & \multirow[t]{2}{*}{92} \\
\hline & & Reverse & CTCCAGCCTCCATTAACTTCTC & \\
\hline Gapdh & Mouse & Forward & AGGTCGGTGTGAACGGATTTG & 123 \\
\hline Cdh1 & Mouse & Reverse & ССAAATCCGATACGTGATCTTCT & 79 \\
\hline \multirow[t]{2}{*}{ Cend1 } & \multirow[t]{2}{*}{ Mouse } & Forward & TCCCCTTGACTGCCGAGAAGT & \multirow[t]{2}{*}{103} \\
\hline & & Reverse & TTCCACTTGAGCTTGTTCA & \\
\hline \multirow[t]{2}{*}{ Myc } & \multirow[t]{2}{*}{ Mouse } & Forward & TGACCTAACTCGAGGAGGAGCTGGAATC & \multirow[t]{2}{*}{170} \\
\hline & & Reverse & AAGTTTGAGGCAGTTAAAATTATGGCTGAAGC & \\
\hline YAP1-S127A & Human transgene & Forward & CCCTCGTTTTGCCATGAACC & 122 \\
\hline
\end{tabular}

doxycycline at P1. Utricles were harvested and fixed on P5 for immunostaining of E-cadherin as described above. High-magnification confocal $z$ stacks of the lateral region were acquired at the boundary of the sensory and nonsensory epithelium. The E-cadherin intensity at SC-SC junctions was obtained by drawing a perpendicular line across at least 30 SC-SC junctions and averaging the peak intensities from the maximal intensity projection. That was divided by the average E-cadherin intensity of at least 30 cell junctions within the nonsensory epithelium within the same image to generate a single normalized E-cadherin intensity value for the utricle, which was considered an independent statistical replicate. Only one utricle was analyzed per mouse.

RNA extraction, reverse transcription, and quantitative PCR

Eight to 14 utricles were dissected in ice-cold PBS until only the sensory epithelia, stroma, and small portion of surrounding nonsensory tissue remained, and combined to serve as one biological replicate. Tissue was transferred to TRIzol (Ambion), and frozen at $-80^{\circ} \mathrm{C}$ until further processing. Upon thawing, tubes were vortexed and chloroform was added. Following centrifugation, the aqueous phase was extracted, mixed 1:1 with isopropanol, supplemented with $20 \mu \mathrm{g} / \mathrm{ml}$ Linear Acrylamide (Ambion), and incubated at $-20^{\circ} \mathrm{C}$ overnight. The following day, RNA was pelleted via centrifugation, washed twice in $1 \mathrm{ml}$ chilled $75 \%$ ethanol, and then resuspended in $20 \mu \mathrm{L} \mathrm{H}_{2} \mathrm{O}$. RNA concentration was assessed using a NanoDrop ND-1000 spectrophotometer, and equal amounts of RNA were used for reverse transcription reactions for each biological replicate. cDNA was synthesized using the iScript cDNA synthesis kit (Bio-Rad). qRT-PCR was performed on a Bio-Rad CFX Connect using iTaq Universal SYBR Green Supermix (Bio-Rad). Primer specificity was determined by melt curve analysis and verified by analyzing amplicon size via gel electrophoresis. Primers are listed in Table 1. The qPCR was performed with two or three technical replicates per sample and at least four biological replicates. Fold change was calculated by the delta-delta $\mathrm{C}_{\mathrm{t}}$ method with Gapdh as the reference gene. For statistical hypothesis testing, the Mann-Whitney test was used with each biological replicate considered an independent observation.

\section{RNAscope ISH}

Utricles from P0, P6, P16, and adult ( $\geq$ P30) mice were dissected on the same day in ice-cold PBS and fixed for $1.5 \mathrm{~h}$ at room temperature in fresh 4\% PFA reconstituted in RNAse-free PBS. Utricles were transferred through a sucrose gradient of RNAse-free PBS supplemented with $5 \%$, $10 \%, 15 \%, 20 \%$, and $30 \%$ sucrose for $2 \mathrm{~h}$ each at $4^{\circ} \mathrm{C}$. Then utricles were incubated with PBS with $30 \%$ sucrose containing two drops of OCT compound, followed by incubation in a 1:1 mixture of PBS with 30\% sucrose and OCT for $1 \mathrm{~h}$. A single utricle from each age group was then transferred to a cryomold filled with chilled OCT, frozen on dry ice, and stored at $-80^{\circ} \mathrm{C}$ until further processing. Utricles were cryosectioned as $10-\mu \mathrm{m}$-thick slices, stored on Superfrost Plus slides (Fisher Scientific), and then stored at $-80^{\circ} \mathrm{C}$ until further processing. The RNAscope Fluorescent Multiplex Assay was performed according to manufacturer's instructions for fixed frozen samples. The probes Mm-Cyp26b1-O1-C3 (\#524001-C3), Mm-Tead1-C1 (\#457371), Mm-Tead2-C1 (\#420281), Mm-Tead3-C2 (custom), and Mm-Tead4-C2 (custom) were ordered from Advanced Cell Diagnostics.

\section{Experimental design and statistical analysis}

All data are displayed as mean $\pm \mathrm{SD}$, unless otherwise noted in the figure legends. Statistical hypothesis testing was performed in GraphPad Prism 8. For comparisons of two experimental groups, two-tailed unpaired $t$ tests were used unless otherwise noted. Paired $t$ tests were used to compare rates of viral transduction and proliferation in striolar and extrastriolar regions. qRT-PCR experiments were analyzed with the nonparametric Mann-Whitney test. Comparisons of three or more experimental groups were analyzed with ANOVA along with pairwise post hoc tests, as indicated in Results and the figure legends. $p$ values $<0.05$ were considered statistically significant. For in vitro experiments, each utricle was considered an independent biological observation (biological replicate), unless otherwise stated in the figure legends, and no methods were used to allocate utricles into treatment groups unless otherwise noted in Results or figure legends. For in vivo experiments, mice of either sex were allocated to experimental groups based on genotype, and each mouse was considered an independent observation. No methods were used for sample size determination. At least three independent biological replicates were used for all statistical comparisons. There was no special determination or handling of outliers. No masking was used for data analysis.

\section{Results}

\section{HC loss leads to nuclear accumulation of YAP in chicken SCs, but not in those of mice}

Since cells regulate the activity of YAP in part by controlling its nuclear access (Shreberk-Shaked and Oren, 2019), we tested whether HC loss would trigger nuclear accumulation of YAP in the SCs that are essential for HC regeneration in posthatch chickens. Utricles were cultured with $1 \mathrm{mM}$ streptomycin for 24 $\mathrm{h}$ to kill HCs and fixed after 2 additional days in streptomycinfree medium. Then $\mathrm{N}: \mathrm{C}$ ratios of YAP immunostaining were computed for confocal images of the SC nuclear layer. Streptomycin treatment reduced the density of HCs to $11 \%$ of the level in untreated control cultures $\left(p<0.0001, t_{(10)}=16.77\right.$, $n=6$ utricles per condition; Fig. $1 A, C, I)$, resulting in a $22 \%$ increase in the N:C ratio of YAP $\left(p<0.0001, t_{(10)}=8.248, n=6\right.$ utricles per condition; Fig. $1 B, D, J)$.

We used the same protocol to determine whether HC loss would induce nuclear translocation of YAP in SCs of the postnatal day 1 (P1) mouse utricle. Here, the streptomycin treatment reduced the $\mathrm{HC}$ density to $55 \%$ of the level in undamaged 

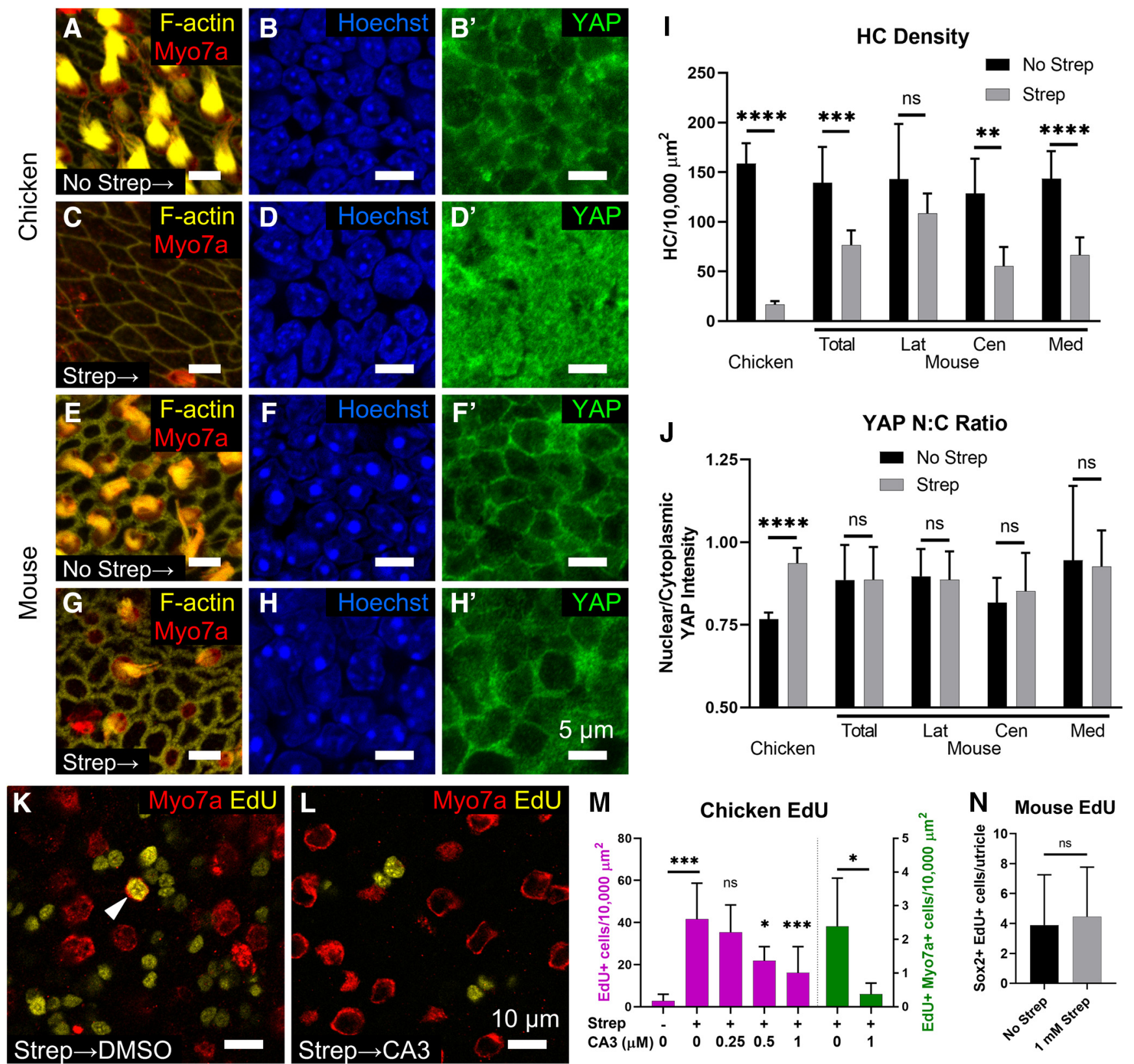

Figure 1. YAP accumulated in SC nuclei after $\mathrm{HC}$ loss and mediated regenerative proliferation in utricles of chickens, but not in those of mice. A-H, Utricles from P2 chickens and P1 mice were cultured $24 \mathrm{~h}$ with or without streptomycin and fixed after $72 \mathrm{~h}$ to assess $\mathrm{HC}$ loss in confocal images of the apical surface and YAP N:C ratios in the SC nuclear layer. Streptomycin induced HC loss in both species, but YAP accumulated in SC nuclei only in damaged chicken utricles (D). The central (putative striolar) region of the mouse utricle was imaged (E-H). $\boldsymbol{I}$, Quantification reveals significant $\mathrm{HC}$ loss in streptomycin-treated utricles of chickens $(p<0.0001, n=6$ utricles) and mice (total: $p=0.0004, n=8)$. Regional comparisons for the mouse utricle were made with Sidak's test (Lat: $p=0.48$; Cen: $p=0.0065$, Med: $p<0.0001, n=6-8)$. J, Quantification of YAP N:C ratios reveals significant increases in streptomycin-treated chicken utricles $(p<$ $0.0001, n=6$ ). Damage had no effect on mouse utricles (total: $p=0.98, n=8$ ). Regional comparisons for the mouse utricle were made with Sidak's test (Lat: $p=0.99 ;$ (en: $p=0.87$, Med: $p=0.996, n=8) . K, \boldsymbol{L}$, Confocal image of streptomycin-treated P2 chicken utricles. Those cultured with DMSO $(\boldsymbol{K})$ contained significantly more EdU ${ }^{+}$cells and Myo7a ${ }^{+}$EdU ${ }^{+}$cells (arrowhead) than those cultured with $1 \mu \mathrm{M} C A 3(\boldsymbol{L})$ through day 7 . M, Quantification of EdU ${ }^{+}$cells after $3 \mathrm{~d}$ (magenta bars, left $y$ axis) and Myo7a ${ }^{+}$EdU ${ }^{+}$cells after $7 \mathrm{~d}$ (green bars, right $y$ axis) within P2 chicken utricles. Streptomycin-treated utricles contained significantly more EdU ${ }^{+}$cells than undamaged utricles $(p<0.0001, t$ test $)$. Streptomycin-treated utricles cultured with the YAP-TEAD inhibitor CA3 contained fewer EdU ${ }^{+}$cells in a dose-dependent manner ( $p=0.001$, ANOVA with Dunnett's multiple comparisons test, $\left.n=6-16\right)$. CA3 treatment significantly reduced mitotic HC production $(p=0.034, n=4)$. $N$, P1 mouse utricles were cultured with or without $1 \mathrm{mM}$ streptomycin for $24 \mathrm{~h}$ and then incubated $72 \mathrm{~h}$ in the presence of EdU. Damage did not significantly affect the density of Sox2 ${ }^{+}$EdU $^{+}$cells $(p=0.73, n=9)$. Data are mean \pm SD. ns $p>0.05,{ }^{*} p<0.05$, ${ }^{* *} p<0.01,{ }^{* * *} p<0.001$, ${ }^{* * * *} p<0.0001$.

control cultures $\left(p=0.0004, t_{(14)}=4.583, n=8\right.$ utricles per condition; Fig. $1 E, G, I)$, but we observed no difference in the N:C ratio of YAP $\left(0.89 \pm 0.10\right.$ vs $0.89 \pm 0.11, p=0.9818, t_{(14)}=$ $0.02327, n=8$ utricles; Fig. $1 F, H, J)$.

To test whether YAP and TEAD mediate regenerative proliferation in chicken utricles, we cultured utricles either with or without streptomycin for $24 \mathrm{~h}$ to kill HCs. Then the utricles were cultured an additional $2 \mathrm{~d}$ in varying concentrations of CA3, a small-molecule inhibitor of YAP-TEAD transcriptional activity (Song et al., 2018). EdU was added $24 \mathrm{~h}$ before fixation to label cells that entered S-phase. The streptomycin-treated utricles contained 15-fold more EdU ${ }^{+}$cells than undamaged controls $(p<$ $0.0001, t_{(20)}=5.48, n=6-16$ utricles; Fig. $\left.1 M\right)$, and the CA3 treatment caused a dose-dependent reduction in that regenerative proliferation $\left(p=0.0010, F_{(3,34)}=2.528, n=7-16\right.$ utricles, ANOVA; Fig. $1 M)$. Other streptomycin-treated utricles that 

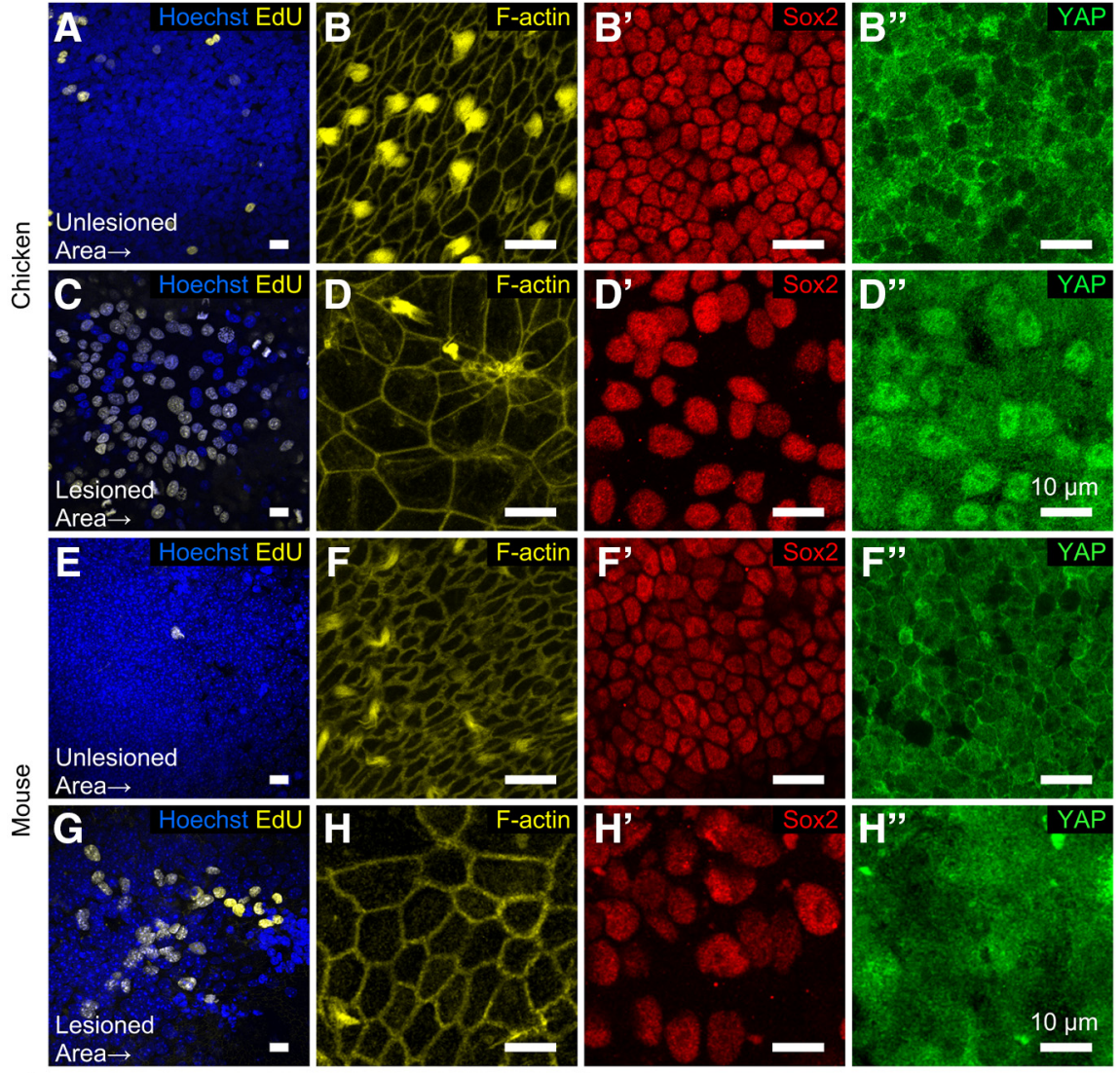

I

Regression - Chicken
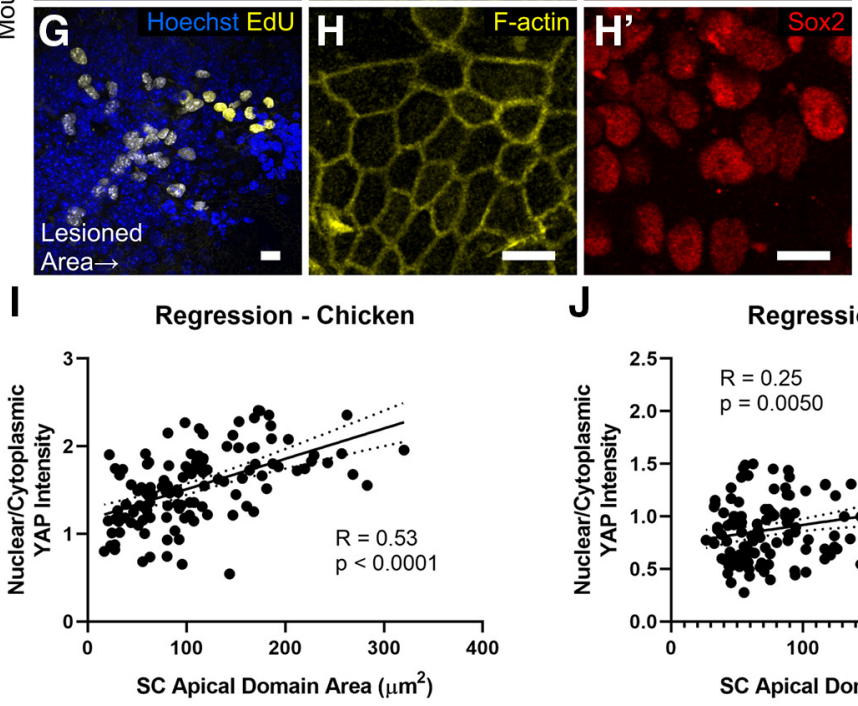

J

Regression - Mouse
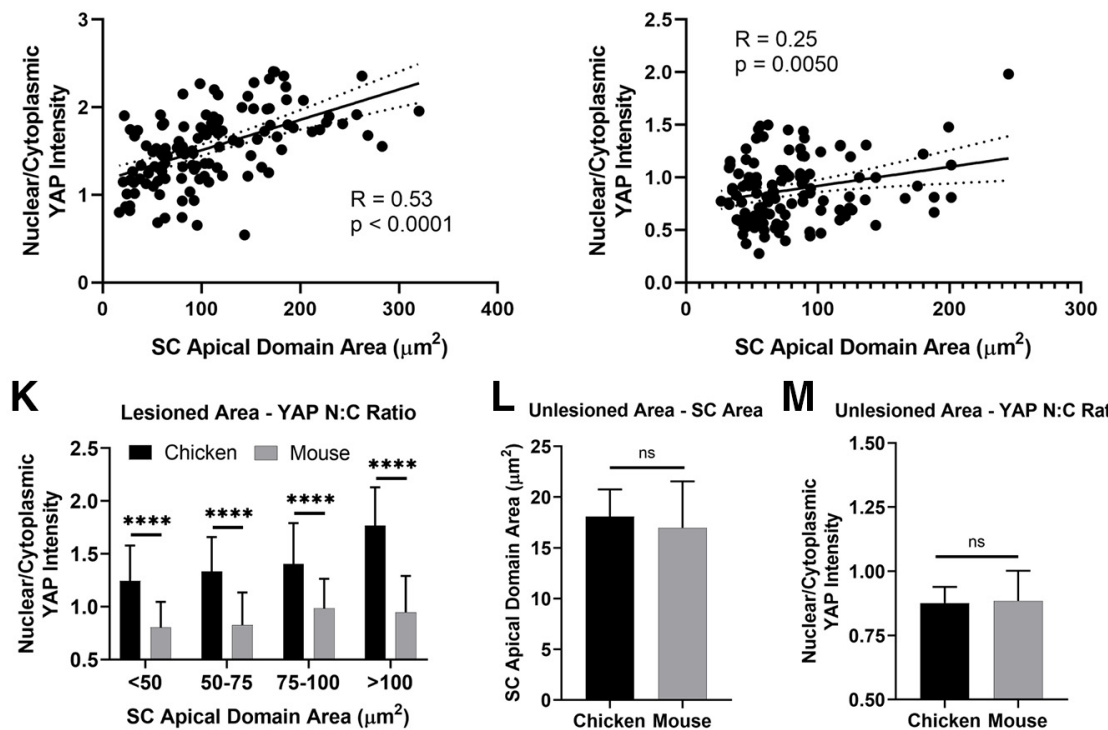

L Unlesioned Area - sc Area

M
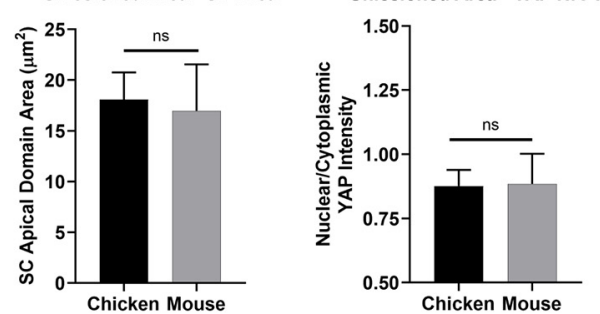

Figure 2. In SCS that changed shape to close excision lesions, nuclear accumulation of YAP was more prominent in chickens than mice. After $24 \mathrm{~h}$ in culture, standardized excision lesions were made in utricles from P2 chickens and P1 mice, which were cultured an additional $48 \mathrm{~h}$ before fixation. $\boldsymbol{A}-\boldsymbol{D}$, Damage evoked a focal proliferative response in the chicken utricle $(\boldsymbol{A}, \boldsymbol{C})$. YAP markedly accumulated in the nuclei of SCS that expanded to close the lesion $(\boldsymbol{D})$ compared with the densely packed SCS outside of the lesioned area $(\boldsymbol{B}) . \boldsymbol{E}-\boldsymbol{H}$, Damage also evoked a focal proliferative response in the mouse utricle $(\boldsymbol{E}, \boldsymbol{G})$. Modest nuclear accumulation of YAP was evident in SCS that expanded to close the lesion in the center of the macula $(\boldsymbol{H})$ compared with those outside of the lesion area at the periphery of the macula $(\boldsymbol{F})$. $\boldsymbol{I}$, Regression analysis revealed a significant association between YAP N:C ratio and SC apical domain size within the lesioned area of the chicken utricle (slope non-zero at $p<0.0001, n=$ 120 cells from 4 utricles). Dashed lines indicate $95 \%$ Cl. J, Regression analysis reveals a modest association between YAP N:C ratio and SC apical domain size within the lesioned area of the mouse utricle (slope non-zero at $p=0.0050, n=120$ cells from 4 utricles). $\boldsymbol{K}$, Quantification of the YAP N:C ratio in SCS within the lesioned area revealed that YAP was significantly enriched in nuclei of SCs of the chicken utricle compared with those of the mouse utricle, controlling for the apical domain area (each $p<$ 0.0001, two-way ANOVA with Sidak's test, $n=19-58$ cells per bin per species). $L$, Quantification of SC apical domain size

were cultured with CA3 for $6 \mathrm{~d}$ contained fewer $\mathrm{EdU}^{+}$cells that expressed the HC marker Myo7a than matched controls $\left(p=0.0337, t_{(6)}=2.741, n=4\right.$ utricles; Fig. $1 K-M)$. In contrast, $\mathrm{HC}$ ablation failed to induce significant regenerative proliferation in P1 mouse utricles during a $3 \mathrm{~d}$ recovery period $(p=$ $0.73, t_{(16)}=0.35, n=9$ utricles; Fig. $\left.1 N\right)$. Together, the results suggest that HC loss in chicken utricles modulated signaling that led to nuclear accumulation of YAP and regenerative proliferation of SCs, but the less severe HC loss in mouse utricles did not.

Mechanical wounds trigger the nuclear accumulation of YAP more potently in chicken SCs than in those of mice As streptomycin killed fewer $\mathrm{HCs}$ in mouse utricles than in chicken utricles, we could not directly compare the nuclear accumulation of YAP in their SCs after damage. To circumvent that issue and test whether damage more readily activates YAP in chicken SCs than murine SCs, we analyzed their responses to a standardized excision lesion. After $24 \mathrm{~h}$ in culture, utricles from posthatch chickens and P1 mice were lesioned with a micropunch $180 \mu \mathrm{m}$ in diameter, and the epithelium within the lesion area was removed (Meyers and Corwin, 2007; Collado et al., 2011a). After an additional $48 \mathrm{~h}$ of culture with EdU, SCs at the lesion site changed shape and proliferated (Fig. 2A,C,E,G). YAP immunoreactivity was enriched in the nuclei of chicken SCs at the lesion site (Fig. 2B,D). The translocation was less pronounced in mouse utricles, with YAP evenly distributed between the nuclear and cytoplasmic compartments of SCs at the lesion site (Fig. 2F,H).

Cellular shape change (i.e. strain) triggers the nuclear translocation of YAP in other cell types (Codelia et al., 2014; Benham-Pyle et al., 2015; Fletcher et al., 2018). To more closely examine the relationship between shape change and nuclear accumulation of YAP in SCs, we measured the apical domain area and YAP N:C ratio for individual SCs at the center of each lesion site. Regression analysis showed that, in SCs of chickens,

outside of the lesioned area revealed no significant difference between chicken and mouse utricles $(p=0.6870$, $n=4$ utricles). $M$, Quantification of YAP N:C ratio from confocal images of the SC nuclear layer in the unlesioned area revealed no significant differences between chicken and mouse utricles ( $p=0.8852, n=4-6$ utricles). All graphs depict mean \pm SD. ${ }^{* * * *} p<0.0001$. 

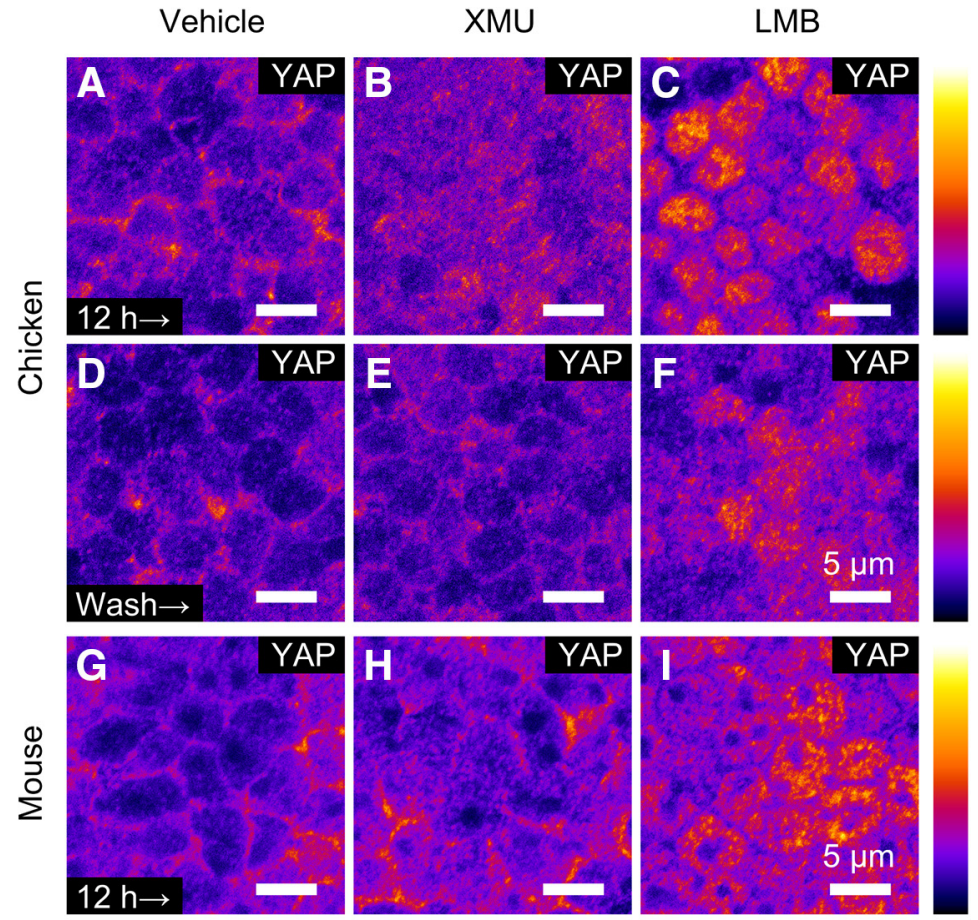

\section{$\mathbf{J}$}
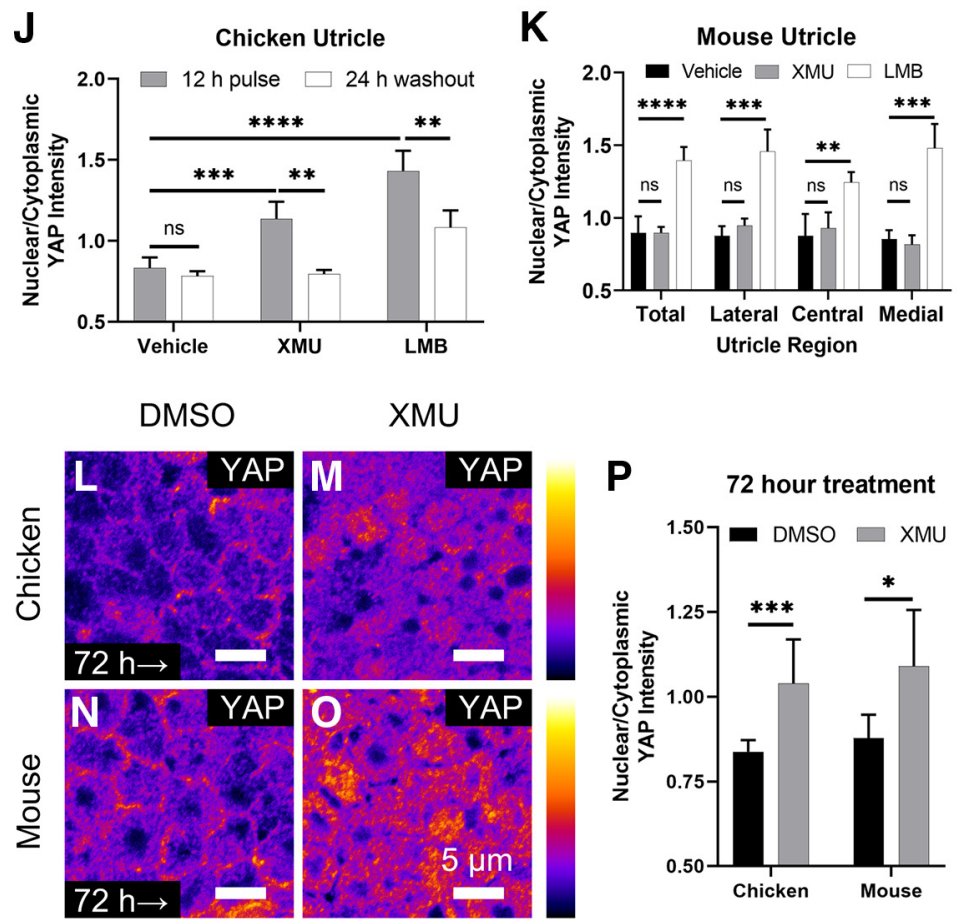

Figure 3. Acute inhibition of MST1/2 kinase activity induced nuclear accumulation of YAP in chicken SCs, but not in those of mice. A-I, High-magnification images of YAP immunoreactivity (pseudocolored) in the SC nuclear layer of explanted P2 chicken utricles $(\boldsymbol{A}-\boldsymbol{F})$ or P1 mouse utricles (G-I) cultured in vehicle negative control, MST1/2 kinase inhibitor XMU-MP-1 (XMU) at 3 $\mu \mathrm{M}$, or leptomycin $B(L M B)$ at $40 \mathrm{ng} / \mathrm{ml}$ as a positive control. After $12 \mathrm{~h}$, YAP intensity is greater in the cytoplasm than in nuclei in vehicle controls $(\boldsymbol{A}, \boldsymbol{G})$, and enriched in nuclei in utricles treated with $L M B(\boldsymbol{C}, \boldsymbol{I})$. XMU treatment increases nuclear levels of YAP to an intermediate extent in the chicken utricle $(\boldsymbol{B})$ and is reversible upon a $24 \mathrm{~h}$ washout $(\boldsymbol{E})$. XMU did not affect YAP $\mathrm{N}: \mathrm{C}$ ratios in the mouse utricle during a $12 \mathrm{~h}$ pulse $(\boldsymbol{H})$. The central (striolar) region of the mouse utricle was imaged $(\boldsymbol{G}-\boldsymbol{I})$. $\boldsymbol{J}$, Quantification shows that a $12 \mathrm{~h}$ pulse of XMU significantly increases the $\mathrm{N}: \mathrm{C}$ ratio of YAP over vehicle controls in chicken utricles ( $p<0.0001, n=5$ utricles, ANOVA with Sidak's test). Washout of XMU reverts the YAP N:C ratio to baseline levels ( $p$ $<0.0001, n=4$ or 5). LMB significantly increases YAP N:C ratio ( $p<0.0001, n=4$ or 5 ). $K$, Quantification reveals that a 12 h treatment with LMB significantly increased the YAP $N: C$ ratio in mouse utricles compared with vehicle (ANOVA with Dunnett's test, $p<0.0001, n=5$ or 6 ), but XMU had no effect (ANOVA with Dunnett's test, $p=0.99, n=6$ ). Repeatedmeasures ANOVA with Dunnett's test was used for region-specific comparisons. $\mathbf{L}-\mathbf{0}$, Confocal images of YAP immunoreactivity from the $S C$ nuclear layer in utricles from P2 chickens $(\boldsymbol{L}, \boldsymbol{M})$ and $\mathrm{P} 1$ mice $(\boldsymbol{N}, \mathbf{0})$ that were cultured in $3 \mu \mathrm{M}$ XMU or DMSO for $72 \mathrm{~h} . \boldsymbol{P}$, Quantification reveals that $72 \mathrm{~h}$ treatment with XMU significantly increased the YAP N:C ratio in chicken utricles the $\mathrm{N}: \mathrm{C}$ ratio of YAP positively correlated with the area of the apical domain $(r=0.531, n=120$ cells, $p<0.0001$; Fig. $2 I)$. There was a significant, but weaker, positive correlation between the YAP $\mathrm{N}$ :C ratio and apical domain area of murine SCs within the lesion site $(r=0.255$, $n=120$ cells, $p=0.005$; Fig. $2 J)$. Chicken SCs had significantly greater $\mathrm{N}$ :C ratios of YAP than murine SCs, even when controlling for cell area $(p<0.0001$, $F_{(1,232)}=147, n=240$ cells, two-way ANOVA; Fig. $2 K$ ). Outside of the lesion site, there were no significant differences in apical area $\left(p=0.69, t_{(6)}=0.42, n=4\right.$ utricles; Fig. $2 L)$ or YAP N:C ratio $(p=$ $0.89, t_{(8)}=0.15, n=4-6$ utricles; Fig. $2 M$ ) between chicken and murine SCs. The results indicate that the nuclear accumulation of YAP in response to damage, and specifically shape change, is restricted in murine SCs relative to those of chickens.

\section{Acute inhibition of MST1/2 kinase} activity alters YAP localization in chicken SCs, but not those of mice In the canonical Hippo pathway, a cascade of MST1/2 and LATS1/2 kinases phosphorylates YAP leading to its cytoplasmic sequestration (Dong et al., 2007). We used XMU-MP-1, a small molecule inhibitor of MST1/2 kinase activity (Fan et al., 2016), to test whether that canonical pathway regulates the nuclear access of YAP in utricles of posthatch chickens and P1 mice. After a 24 hour acclimation period in standard medium, we treated cultures for $12 \mathrm{~h}$ with XMU-MP-1, vehicle, or the nuclear export blocker leptomycin B as a positive control (Dupont et al., 2011). Leptomycin B significantly increased the $\mathrm{N}: \mathrm{C}$ ratio of YAP in both species, indicating that YAP shuttles dynamically into and out of SC nuclei in the undamaged utricles of chickens and mice (chicken: $p<0.0001, F_{(5,20)}=37, n$ $=4$ or 5 , ANOVA; mouse: $p<0.0001$, $F_{(2,14)}=56$, ANOVA, $n=5$ or 6 ; Fig. $3 A-$ $K)$. In the chicken utricles, MST1/2 inhibition led to a significant increase in the YAP N:C ratio compared with negative controls $(1.14 \pm 0.10$ vs $0.83 \pm 0.07, p<$ 0.0001 , ANOVA with Sidak's test; Fig. $3 A, B)$, which was reversible after a $24 \mathrm{~h}$ washout $(p<0.0001$, ANOVA with

\section{$\leftarrow$}

$(p=0.0008, n=8)$ and mouse utricles $(p=0.0103, n=$ 6 or 7) compared with DMSO-treated controls. Data are mean \pm SD. ns $p>0.05,{ }^{*} p<0.05,{ }^{* *} p<0.01,{ }^{* * *} p$ $<0.001,{ }^{* * * *} p<0.0001$. 
Sidak's test; Fig. 3E,J). We did not observe an increase in the YAP N:C ratio in mouse utricles after a $12 \mathrm{~h}$ incubation with the MST1/2 inhibitor $(0.90 \pm 0.11$ vs $0.90 \pm 0.04, p=0.9997, n=6$ utricles, ANOVA with Dunnett's test; Fig. $3 G, H)$, although a 72 $h$ incubation significantly increased the $\mathrm{N}$ :C ratios of YAP in both species compared with DMSO-treated controls (chicken: $1.04 \pm 0.13$ vs $0.84 \pm 0.03, p=0.0008, t_{(14)}=4.23, n=8$ utricles; mouse: $1.09 \pm 0.17$ vs $0.88 \pm 0.07, p=0.0103, t_{(11)}=3.09, n=6$ or 7 utricles; Fig. $3 L-P$ ). The results suggest that canonical Hippo signaling is required for the cytoplasmic sequestration of YAP in chicken SCs. This inhibitory signaling was readily inactivated or bypassed upon damage, leading to the nuclear accumulation of YAP (Fig. 1). In murine SCs, however, the cytoplasmic sequestration of YAP was less sensitive to damage or the acute inhibition of MST1/2.

\section{YAP-S127A induces YAP-TEAD transcriptional activity and SC proliferation in neonatal mouse utricles}

Our findings to this point suggested that YAP was restricted to the cytoplasm in murine SCs despite HC loss and acute inhibition of MST1/2. We hypothesized that overexpression of YAPS127A, which contains an activating mutation at serine 127 that prevents binding to 14-3-3 proteins and retention in the cytoplasm (Basu et al., 2003), could bypass this regulation. For this, we crossed mice with an inducible Yap-S127A allele to Sox10 ${ }^{r t T A /+}$ mice to generate progeny in which the transgene would be expressed in SCs and other Sox $10^{+}$cells only upon administration of doxycycline (Ludwig et al., 2004; Camargo et al., 2007; Walters and Zuo, 2015). We injected doxycycline intraperitoneally to P1 offspring and supplemented the dam's drinking water. EdU was injected subcutaneously on P2, P3, and P4, and utricles were harvested on P5. In the SCs of Yap-S127 ${ }^{+/-}$; So $10^{r t T A /+}$ mice, YAP immunoreactivity was visibly increased compared with SCs in utricles from WT, Sox $10^{r t T A /+}$, and Yap$S 127 A^{+/-}$littermates (Fig. 4A-D). Moreover, the utricles of Yap-S127A $A^{+/-}$;Sox $10^{\text {rtTA/P }}$ pups exhibited a 35-fold increase in $\mathrm{EdU}^{+}$cells over the littermate controls $\left(97 \pm 54 \mathrm{EdU}^{+}\right.$cells/ $10,000 \mu \mathrm{m}^{2}, p<0.0001, F_{(3,27)}=20.8, n=5-11$ mice, ANOVA; Fig. $4 A-E$ ). Those EdU ${ }^{+}$cells expressed the SC marker Sox2 (Fig. $\left.4 \mathrm{D}^{\prime \prime \prime}\right)$. EdU ${ }^{+}$SCs were located throughout the utricle but were slightly enriched in the lateral region $\left(p=0.0011, F_{(2.9,43.1)}=6.5\right.$, $n=16$ utricles, repeated-measures ANOVA with Tukey's test; Fig. $4 F)$. It has been previously shown that cells along the lateral edge of the utricle are the last to exit the cell cycle in postnatal mice (Burns et al., 2012b).

To determine whether YAP-S127A would induce YAPTEAD transcriptional activity, we gave doxycycline as described above and harvested utricles on P3 for qRT-PCR. Compared with littermate controls, the YAP-TEAD target genes Ctgf, Cyr61, and Ankrd1 were upregulated in the utricles from the Yap-S127A ${ }^{+/-}$;Sox $10^{\text {rtTA/+ }}$ mice by 32 -fold, 7-fold, and 181-fold, respectively ( $p=0.0286$, Mann-Whitney test; Fig. 4G). Myc expression was unchanged ( $p=0.4571$, Mann-Whitney test), and the cell cycle regulator $C$ cnd 1 was upregulated 3-fold $(p=0.0286$, Mann-Whitney test; Fig. 4H).

We next sought to determine whether the proliferating SCs in Yap-S127A ${ }^{+/-}$;Sox $10^{r t T A /+}$ mice would be able to differentiate as HCs. Since Yap-S127A $A^{+/-}$; Sox $10^{r t T A /+}$ pups that were administered doxycycline on P1 did not consistently tolerate the treatment beyond P5, we modified our protocol to circumvent this toxicity and administered a reduced dose of doxycycline (10 mg/ $\mathrm{kg}$ ) to Yap-S127 ${ }^{+/-}$;Sox $10^{\text {rtTA/+ }}$ mice and littermate controls at $\mathrm{P} 3$. EdU was supplied on P4, P5, and P6, and utricles were harvested at P24. Utricles of Yap-S127A $A^{+/-}$;Sox10 ${ }^{r t T A /+}$ mice contained $7 \pm 4 \mathrm{Myo}^{+}{ }^{+}, \mathrm{EdU}^{+}$cells/10,000 $\mu \mathrm{m}^{2}$, 49-fold more than littermate controls $\left(p=0.0006, t_{(9)}=5.2, n=3-8\right.$ mice; Fig.
$4 I-L)$. Contralateral utricles that were immunostained for Myo6 contained 40-fold more $\mathrm{Myo6}^{+}, \mathrm{EdU}^{+}$cells than littermate controls $\left(p<0.0001, t_{(8)}=7.4, n=3-7\right.$ mice; Fig. $\left.4 K\right)$. Thus, reactivating YAP-TEAD signaling in SCs of the neonatal mouse utricle spurs them to generate progeny that express HC markers in vivo.

YAP-TEAD transcriptional activity can also induce negative feedback (Dai et al., 2015; Moroishi et al., 2015; Park et al., 2016). $\mathrm{E}$-cadherin is reported to be a negative regulator of YAP in other epithelia (Kim et al., 2011; Benham-Pyle et al., 2015), and is hypothesized to restrict the activity of YAP in SCs of the mammalian utricle (Kozlowski et al., 2020). To test whether expression of YAP-S127A affects E-cadherin expression, we administered doxycycline to Yap-S127A ${ }^{+/-}$;Sox $10^{\text {rtTA/+ }}$ mice and littermate controls at P1. At P5, the intensity of E-cadherin immunostaining at SC-SC junctions tripled in $\mathrm{Yap}_{\mathrm{S}} \mathrm{S} 127 \mathrm{~A}^{+/-}$; Sox $10^{r t T A /+}$ utricles compared with littermate controls $(p=0.0002$, $t_{(22)}=4.4, n=12$ mice; Fig. $\left.5 A-C\right)$. In utricles that were harvested at P3 for qRT-PCR, transcript levels of E-cadherin were double those of controls ( $p=0.0286$, Mann-Whitney test, $n=4$; Fig. $5 D)$.

High cell density has been proposed to inactivate YAP-TEAD signaling in the developing murine utricle (Gnedeva et al., 2017). To determine whether the induction of YAP-S127A at P1 overcame this regulation, we administered doxycycline to YapS127A $A^{+/-}$; Sox $10^{r t T A /+}$ mice and littermate controls at P1. Then we harvested utricles at P5 and immunostained for the $\mathrm{HC}$ marker Myo7a as well as ZO-1 to delineate apical junctions. The macular area did not significantly change as a result of YAPS127A induction (Control: $0.15 \pm 0.02 \mathrm{~mm}^{2}$ vs YAP-S127A: $0.11 \pm 0.05 \mathrm{~mm}^{2}, p=0.208, t_{(7)}=1.4, n=4$ or 5 mice; Fig. $\left.5 E\right)$, but the spatial density of SCs increased 1.4-fold $\left(p=0.008, t_{(10)}=\right.$ $3.3, n=5-7$ mice; Fig. $5 F-H)$. The total cell density increased 1.25 -fold $\left(p=0.033, t_{(10)}=2.5\right)$, and the density of HCs was unchanged $\left(p=0.36, t_{(10)}=0.96\right)$. The results indicate that mutation of serine 127 to a nonphosphorylatable residue bypassed density-dependent inhibition, enhancing YAP-TEAD transcriptional activity and driving SCs in the neonatal mouse utricle to proliferate.

\section{The proliferative response to YAP-S127A declines during postnatal maturation}

Expression of YAP-S127A stimulated TEAD-dependent transcription and SC proliferation in neonatal mouse utricles, but it was unclear whether SCs would remain responsive as they mature and enter a more persistent state of quiescence. To test that, we injected doxycycline intraperitoneally in one group of Yap$S 127 A^{+/-}$;Sox $10^{r t T A /+}$ mice on $\mathrm{P} 3$, another group on $\mathrm{P} 5$, and a third on P9. EdU was injected subcutaneously once daily over the following $3 \mathrm{~d}$, and the utricles were harvested $4 \mathrm{~d}$ after doxycycline. Following induction on P3, utricles of $\mathrm{Yap}-\mathrm{S} 127 \mathrm{~A}^{+/-}$; Sox $10^{r t T A /+}$ mice contained 95 -fold more $\mathrm{EdU}^{+}$cells than littermate controls. The incidence of S-phase entry fell to less than half of that level following induction on P5, and declined to $5 \%$ of the P3 level when induced on P9 $\left(p<0.0001, F_{(2,56)}=61\right.$, two-way ANOVA, $n=5-16$ mice; Fig. $6 A-G)$.

One potential confounding variable in this in vivo experiment was that the bioavailability of doxycycline in the ear is reported to decline during postnatal maturation (Walters and Zuo, 2015). We confirmed that the YAP-S127A transgene was expressed at all time points by comparing YAP immunoreactivity in the utricles of Yap-S127A $A^{+/-}$;Sox $10^{r t T A /+}$ mice to those of agematched littermate controls (Fig. 6A-F). To circumvent any bioavailability issue, we cultured utricles from P1 and P9 
Wild Type
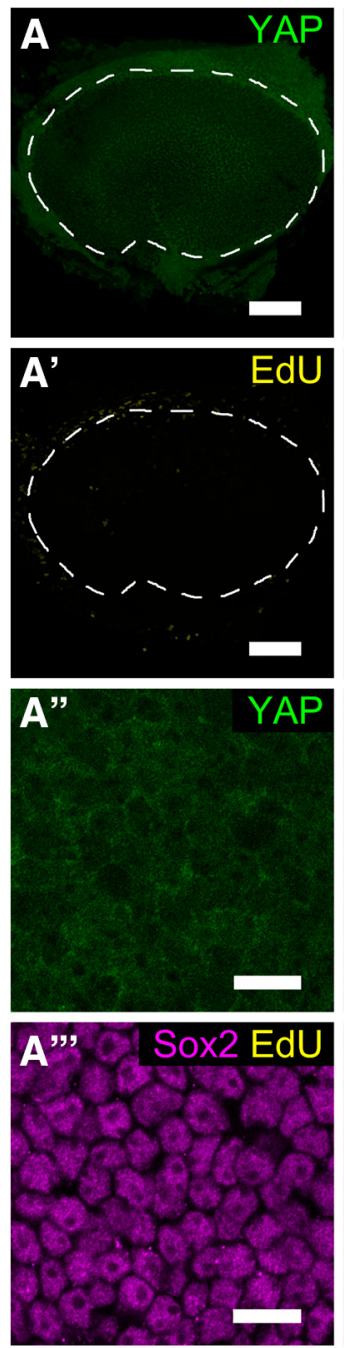

Control
So $10^{r t T A /+}$
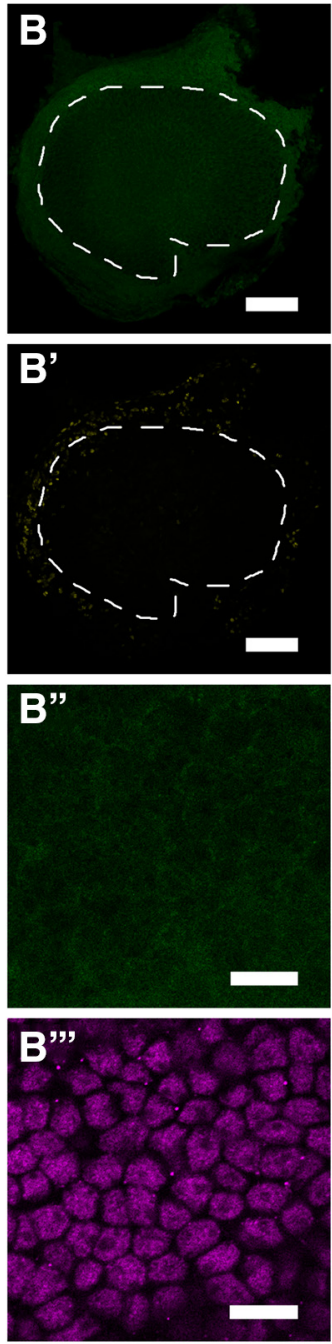

Yap-S127A $A^{+/-}$;Sox $10^{\text {rtTA/+ }}$
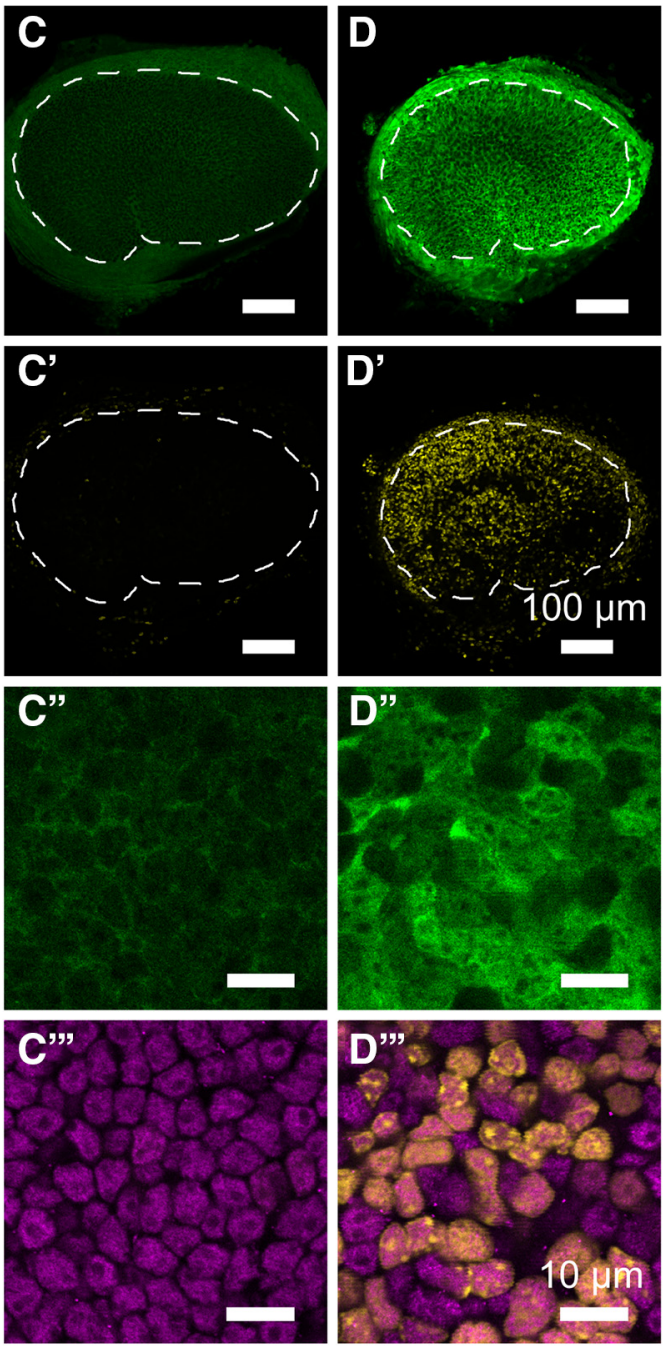
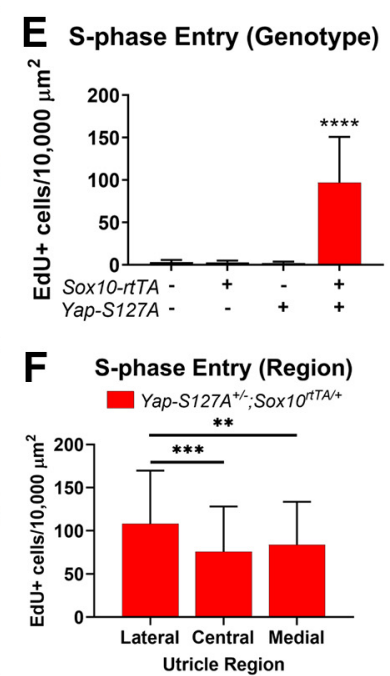

G YAP-TEAD Target Genes
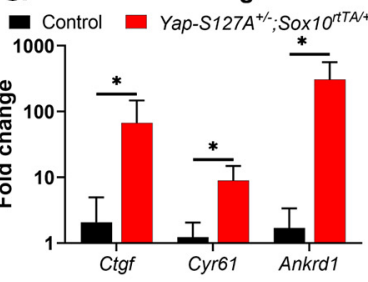

H Cell Cycle Genes
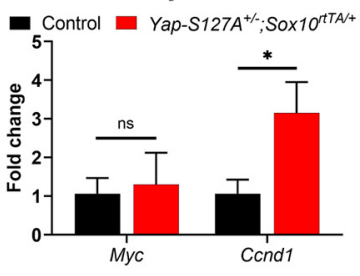
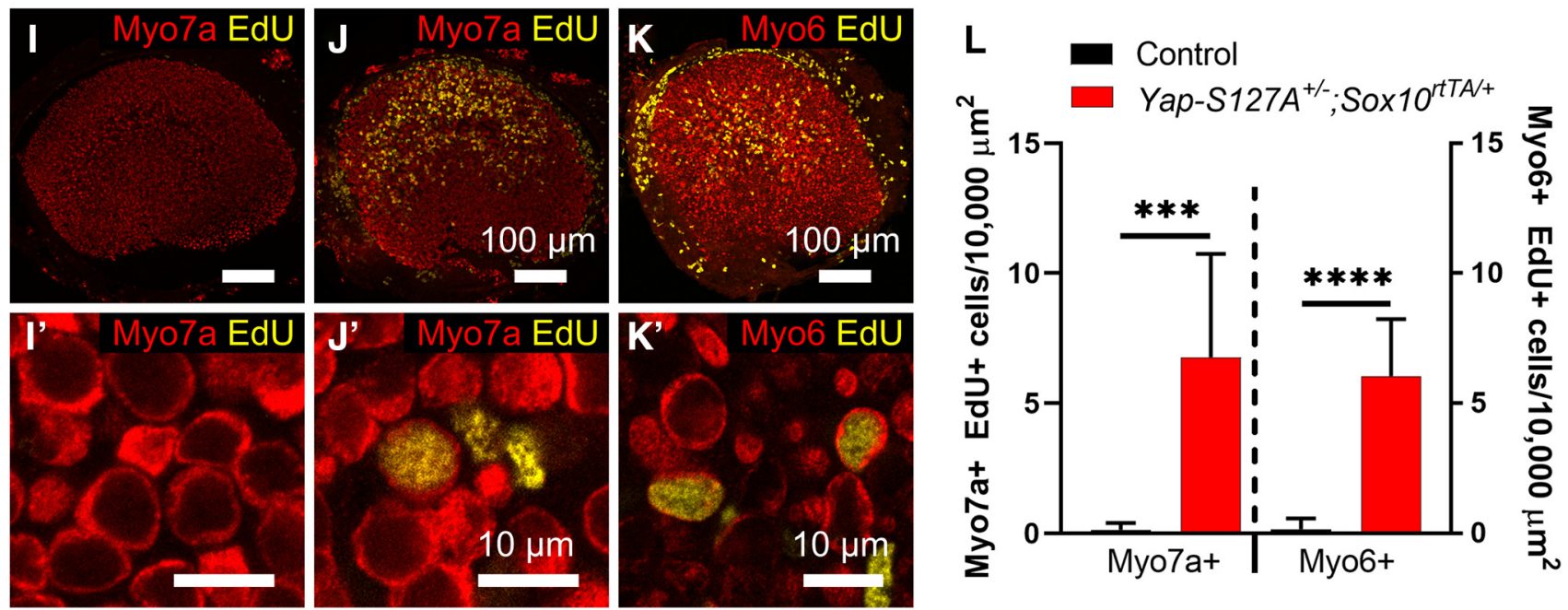

Figure 4. In vivo overexpression of YAP-S127A in the neonatal mouse utricle resulted in widespread S-phase entry, upregulation of YAP-TEAD target genes, and generation of progeny that expressed HC markers. A-D, Doxycycline was administered on P1 and supplemented in the dam's drinking water. EdU was supplied on P2, P3, and P4, and utricles were harvested on P5. A-D, Low-magnification images show that YAP immunoreactivity was more intense in Yap-S127A ${ }^{+/-}$;Sox $10^{\text {tTA/+ }}$ mice $(\boldsymbol{D})$ compared with littermate controls $(\boldsymbol{A}$ - $\boldsymbol{C}$ ), indicating induction of YAPS127A expression. Dashed outlines indicate the boundary of the macula as evident by YAP-negative $\mathrm{HC}_{\text {somas. EdU }}^{+}$cells were abundant within the maculae of Yap-S127A ${ }^{+/-} ;$Sox $10^{\text {rtTA }+}$ mice $\left(\boldsymbol{D}^{\prime}\right)$ but were rare in other genotypes $\left(\boldsymbol{A}^{\prime}-\boldsymbol{C}^{\prime}\right)$. High-magnification confocal images of the SC nuclear layer in the lateral extrastriolar region of the utricle show immunoreactivity for YAP $\left(\boldsymbol{A}^{\prime \prime}-\boldsymbol{D}^{\prime \prime}\right)$ and the SC marker Sox2 with EdU $\left(\boldsymbol{A}^{\prime \prime \prime}-\boldsymbol{D}^{\prime \prime \prime}\right)$. $\boldsymbol{E}$, Quantification of EdU ${ }^{+}$cells revealed utricles of Yap-S127A ${ }^{+/-} ;$Sox $10^{r t T A /+}$ mice had significantly greater S-phase entry (range 
Yap-S127A ${ }^{+/-}$;Sox $10^{r t T A /+}$ mice in the presence of $10 \mu \mathrm{g} / \mathrm{ml}$ doxycycline and EdU for $72 \mathrm{~h}$. Utricles from the P1 mice contained 7fold more Sox ${ }^{+} \mathrm{EdU}^{+}$cells than utricles from the P9 mice $(p=$ $0.0277, t_{(13)}=2.48, n=6-9$; Fig. $\left.6 H-J\right)$, indicating that postnatal maturational changes in the utricle limit SC proliferation in response to YAP-S127A overexpression both in vivo and in vitro. However, it appeared that striolar SCs, which are located in the central region of the utricle, remained responsive to YAP-S127A, even at P9 (Fig. 6I).

To determine whether the age-dependent decrease in proliferation correlated with a decrease in YAP-TEAD transcriptional activity, we cultured utricles of P1 and P9 mice with doxycycline for $48 \mathrm{~h}$ and measured the expression of YAP-TEAD target genes using qRT-PCR. The expression of most target genes declined with age both in utricles from Yap-S127A ${ }^{+/-} ;$Sox $10^{r t T A /+}$ mice and littermate controls (Fig. 6K). However, YAP-S127A induction at $\mathrm{P9}$ still resulted in a 4 -fold to 5-fold increase in expression of the target genes compared with age-matched controls (each $p=$ 0.0286, $n=4$ biological replicates, Mann-Whitney test), indicating that a transcriptional response remained intact. Together, the data suggest that the responsiveness of SCs to YAP-TEAD signaling declines with age but is not eliminated by $\mathrm{P} 9$.

We examined expression patterns of the TEAD transcription factors to characterize their age-related changes in the utricle. RNAscope FISH revealed that TEAD1 was broadly expressed at P0, P6, and P16 (Fig. 7A-C). TEAD2 was expressed throughout the mouse utricle at P0, but expression was lower at P6 and nearly absent at P16 (Fig. 7D-F). The age-related downregulation of TEAD2 correlated with declines in YAP-TEAD transcriptional activity and proliferation, and was consistent with published RNAseq (Gnedeva and Hudspeth, 2015). TEAD3 and TEAD4 transcripts were not detected (data not shown). An antibody specific for TEAD1 labeled nuclei of SCs in newborn and adult mouse utricles (Fig. $7 G, H$ ). Immunostaining of utricles from newborn and adult mice showed that YAP too remained expressed in adult SCs (Fig. $7 I, J$ ), which we confirmed in a human specimen (Fig. $7 K)$. The continued expression of YAP and TEAD1 in adults raised the possibility that SCs in mature mammalian utricles may remain sensitive to YAP-TEAD signaling.

\section{YAP-5SA triggers TEAD-dependent proliferation in utricles from adult mice}

YAP-5SA contains five serine-to-alanine mutations, which allow it to evade inhibitory phosphorylation that leads to cytoplasmic sequestration and degradation (Zhao et al., 2007, 2009, 2010). It

13-182 $\mathrm{EdU}^{+}$cells $\left./ 10,000 \mu \mathrm{m}^{2}\right)$ than littermate controls $(p<0.0001$, ANOVA, $n=5-11$ mice per genotype). $\boldsymbol{F}$, Quantification of S-phase entry by utricular region (ANOVA with Tukey's test, $n=16$ utricles). $\mathbf{G}, \boldsymbol{H}$, Pups were injected with doxycycline at P1, and utricles were harvested on P3 for qRT-PCR. Utricles from WT, Yap-S127A ${ }^{+/}$, and Sox $10^{\text {bTtA }}$ pups were pooled as a negative control. Expression of YAP-TEAD target genes (tgf, Cyr61, and Ankrd1 (G) was significantly upregulated in Yap-S127 ${ }^{+/} ;$SOX $10^{t T T A+}$ mice compared with negative controls (each $p=0.0286$, Mann-Whitney test, $n=4$ biological replicates). Expression of C(nd1, but not Myc, significantly increased in the context of YAP-S127A overexpression $(\boldsymbol{H})(p=0.0286$, Mann-Whitney test, $n=4$

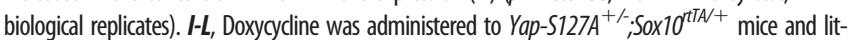
termate controls at P3, and EdU was supplied at P4, P5, and P6. Utricles were harvested at P24.

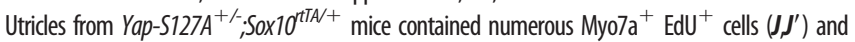

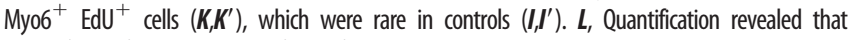
$\mathrm{Myo7a}^{+} \mathrm{EdU}^{+}$cells and Myo6 ${ }^{+} \mathrm{EdU}^{+}$cells were significantly more abundant upon YAP-S127A overexpression at P3 (Myo7a: $p=0.0006, n=3-8$ mice; Myo6: $p<0.0001, n=3-7$ mice). Utricles from WT, Yap-S127A ${ }^{+\kappa}$, and Sox $10^{\text {tTTA+ }}$ pups were pooled to serve as a negative control. Data are mean \pm SD. ns $p>0.05,{ }^{*} p<0.05,{ }^{* *} p<0.01,{ }^{* * *} p<0.001,{ }^{* * * *} p<$ 0.0001 . also more potently stimulates YAP-TEAD signaling than YAPS127A (Zhao et al., 2009). We explanted utricles from P30 mice and adenovirally transduced SCs with YAP-5SA. Matched utricles were transduced with mCherry as a negative control, or WT YAP to evaluate the effect of inhibitory phosphorylation. The rate of SC transduction did not differ between the viruses $\left(p=0.62, F_{(3,12)}=0.61\right.$, ANOVA, $n=4$ utricles; Fig. $\left.8 A\right)$, with $\sim 30 \%$ of SCs and $<1 \%$ of HCs transduced at the titer used (data not shown), consistent with previous reports (Burns et al., 2012c). After $3 \mathrm{~d}$ of culture in the presence of BrdU, utricles that were transduced with mCherry or WT YAP averaged $<2$ Sox $2^{+}$ $\mathrm{BrdU}^{+}$cells (Fig. $8 B-F$ ). In contrast, utricles transduced with YAP-5SA averaged $69 \pm 56\left(p<0.0001, F_{(3,44)}=15, n=10-16\right.$, ANOVA; Fig. $8 D, F)$. The Sox ${ }^{+} \mathrm{BrdU}^{+}$cells lacked hair bundles, suggesting that they were SCs and not Type II HCs (data not shown).

We measured $\mathrm{N}: \mathrm{C}$ ratios of YAP in transduced cells, which expressed an mCherry reporter. SCs transduced with YAP-5SA exhibited significantly higher $\mathrm{N}: \mathrm{C}$ ratios compared with SCs transduced with WT YAP $\left(p=0.0446, F_{(2,9)}=10.5, n=4\right.$, ANOVA with Tukey's test; Fig. $8 G-J)$. In addition, an antibody specific for phospho-YAP (S127) strongly labeled the cytoplasm of SCs transduced with WT YAP, but not those transduced with YAP-5SA in which that epitope is mutated (Fig. $8 K, L$ ). These results show that ectopic WT YAP is phosphorylated and retained in the cytoplasm, whereas YAP-5SA, which lacks inhibitory phosphorylation sites, enters SC nuclei and promotes S-phase entry.

To test whether the TEAD transcription factors were required for the proliferation induced by YAP-5SA, we transduced P30 utricles with YAP-5SA/S94A, which contains the serine-to-alanine mutations of YAP-5SA plus a mutation at residue 94 that abolishes the YAP-TEAD interaction (Zhao et al., 2008). Immunolocalization showed that YAP-5SA/S94A was significantly enriched in SC nuclei relative to ectopic WT YAP $\left(p=0.0036, F_{(2,9)}=10.5, n=4\right.$, ANOVA with Tukey's test; Fig. $8 I, J)$, but no cell cycle reentry occurred (Fig. 8E,F). Together, the results suggested that liberating YAP from inhibitory phosphorylation would allow it to promote TEAD-dependent proliferation in mature striolar SCs.

Cell cycle reentry in response to YAP-5SA preferentially occurred in the striolar region. In utricles transduced with YAP5SA and immunostained for BrdU and the striolar SC marker Tectb after $5 \mathrm{~d}$ in culture, the density of $\mathrm{BrdU}^{+}$cells was $>3$-fold greater in the $\mathrm{Tectb}^{+}$region compared with the Tectb- region $\left(p=0.0001, t_{(4)}=15.3, n=5\right.$, paired $t$ test; Fig. 9). There was no significant difference in the density of transduced SCs between the striolar and lateral extrastriolar region (lateral: $83 \pm 22$; striolar: 83 $\pm 20 \mathrm{SCs} / 10,000 \mu \mathrm{m}^{2}, p=0.90, t_{(3)}=0.14, n=4$, paired $t$ test). We attempted to determine whether the proliferating SCs would differentiate into HCs, however constitutive overexpression of YAP5SA disrupted the morphology of the striola in cultures maintained $5 \mathrm{~d}$ or longer after transduction (Fig. 9A), precluding such analysis.

\section{Conditional KO of LATS1 and LATS2 stimulates proliferation in postnatal murine utricles}

LATS1 and LATS2 are the major kinases that mediate inhibitory phosphorylation of YAP at HXRXXS motifs, thereby regulating its localization and stability (Zhao et al., 2007, 2010). We detected phospho-YAP (S127) immunoreactivity, a measure of LATS kinase activity (Zhao et al., 2007), in SCs throughout the utricles of newborn and adult mice (Fig. $10 A, B$ ), so we hypothesized that inactivation of LATS1/2 would lead to cell cycle reentry in the postnatal murine utricle. We used an in vitro approach to test that, because the Lats $1^{\text {flox/flox }}$ Lats $2^{\text {flox/flox }} ;$ Plp1-Cre ${ }^{\text {ERT2 }}$ 
Control

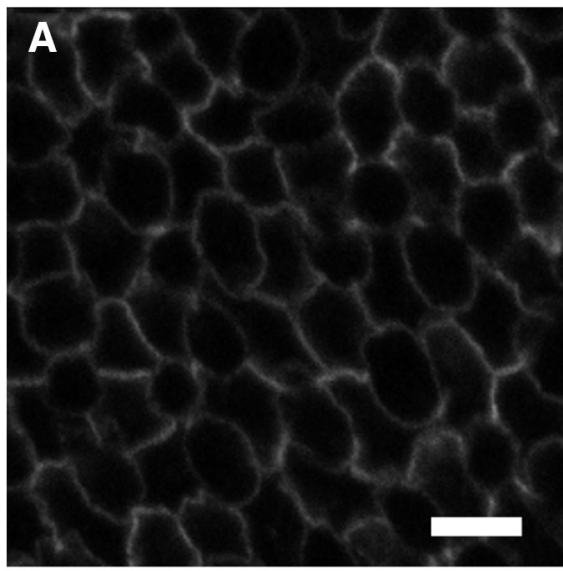

C E-cadherin Intensity
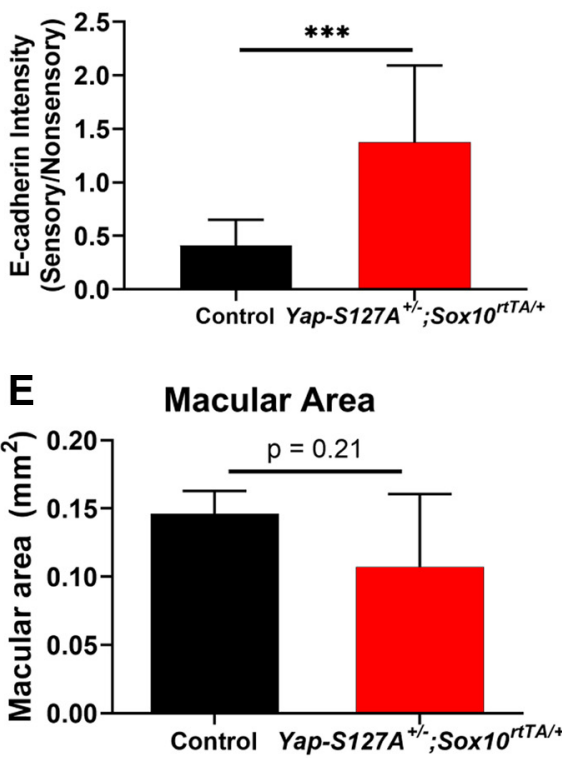

Control

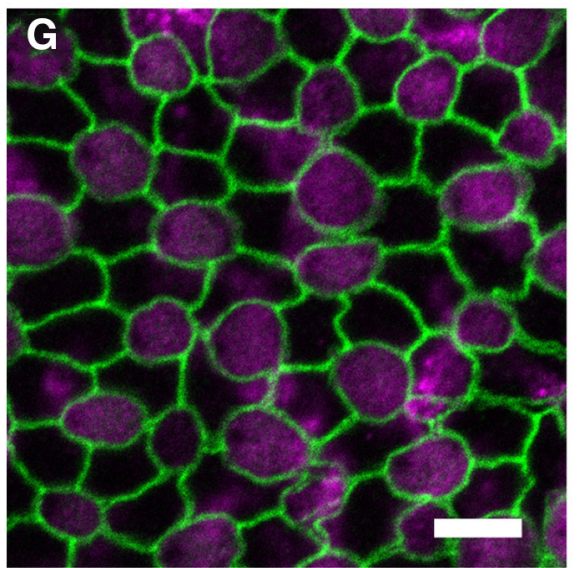

Yap-S127A $A^{+/-}$;Sox $10^{\text {rtTA/+ }}$

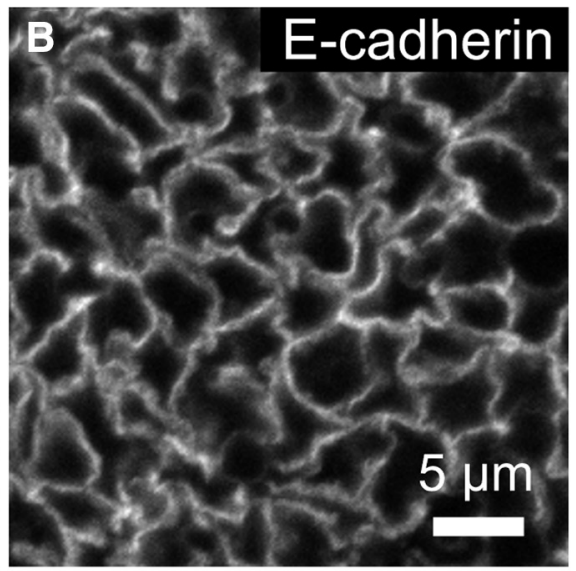

D Cdh1 Gene Expression

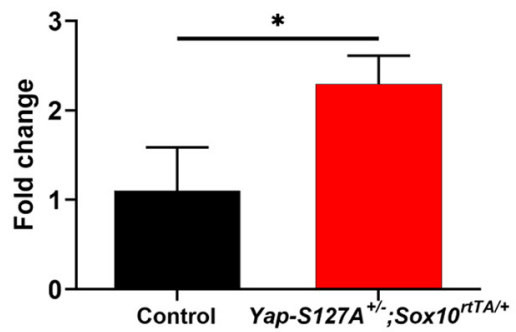

F Cell Density

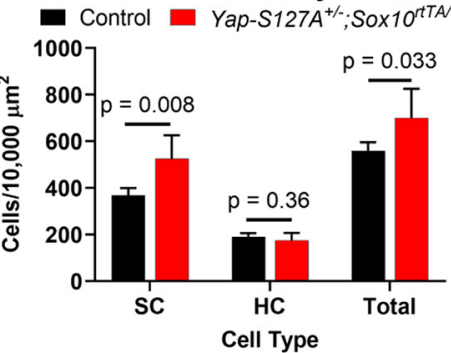

Yap-S127A $A^{+/-} ;$Sox $10^{\text {rtTA/+ }}$

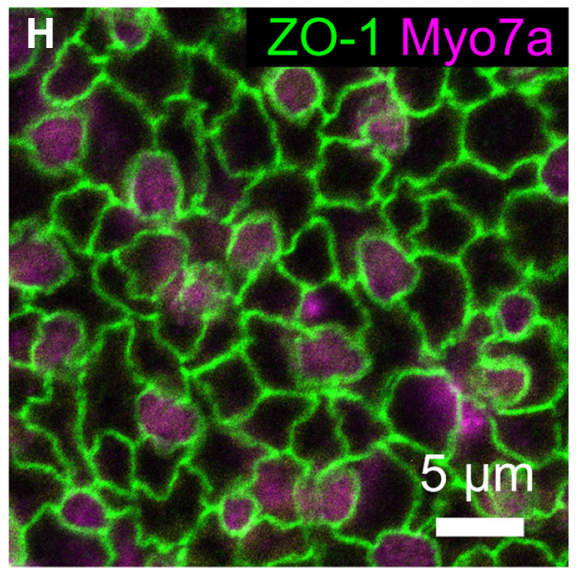

Figure 5. YAP-S127A overexpression at P1 led to upregulation of E-cadherin in SCS and drove an increase in cell density. Doxycycline was administered to Yap-S127A ${ }^{+/-}$;Sox10 ${ }^{r t T /+}$ mice and littermate negative controls at P1, and utricles were harvested either on P5 for immunohistochemistry or on P3 for qRT-PCR. $\boldsymbol{A}, \boldsymbol{B}$, The intensity of E-cadherin immunolabeling in utricles of

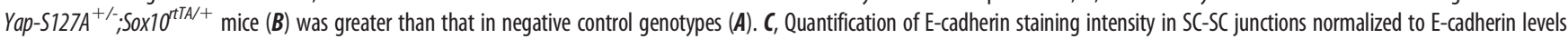
in the nonsensory epithelium as an internal control ( $p=0.022, t$ test, $n=12$ utricles). $\boldsymbol{D}$, Quantification of (dh1 mRNA expression relative to Gapdh reveals that expression doubles in Yap$S 127 A^{+/-}$;Sox $10^{r t T A}+$ mice compared with negative control littermates ( $p=0.0238$, Mann-Whitney test, $n=4$ biological replicates). $\boldsymbol{E}$, Quantification of macular area as defined by Myo7a ${ }^{+}$ labeling reveals no significant differences between utricles from Yap-S127A ${ }^{+/} ;$;ox $10^{\text {tTA } /+}$ mice and controls $(p=0.21, n=4$ or 5 mice). $\boldsymbol{F}, 0$ uantification reveals that the total cell density 
P3-7
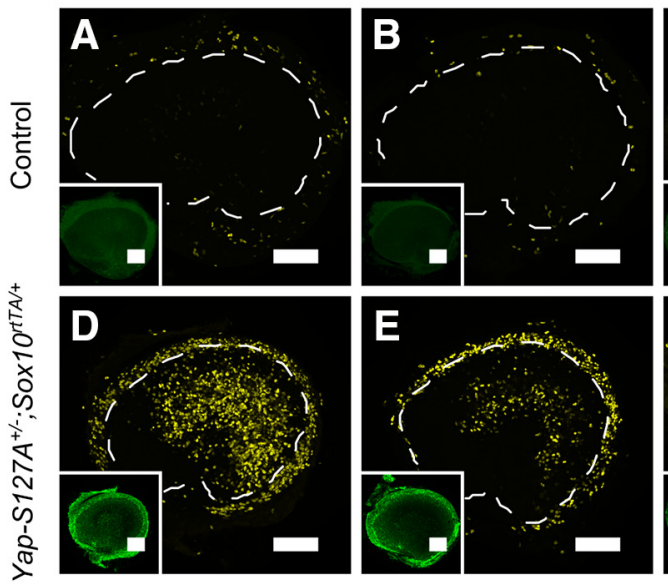

Yap-S127A $A^{+-} ;$Sox $10^{r T A /+}$ in vitro
P9-13
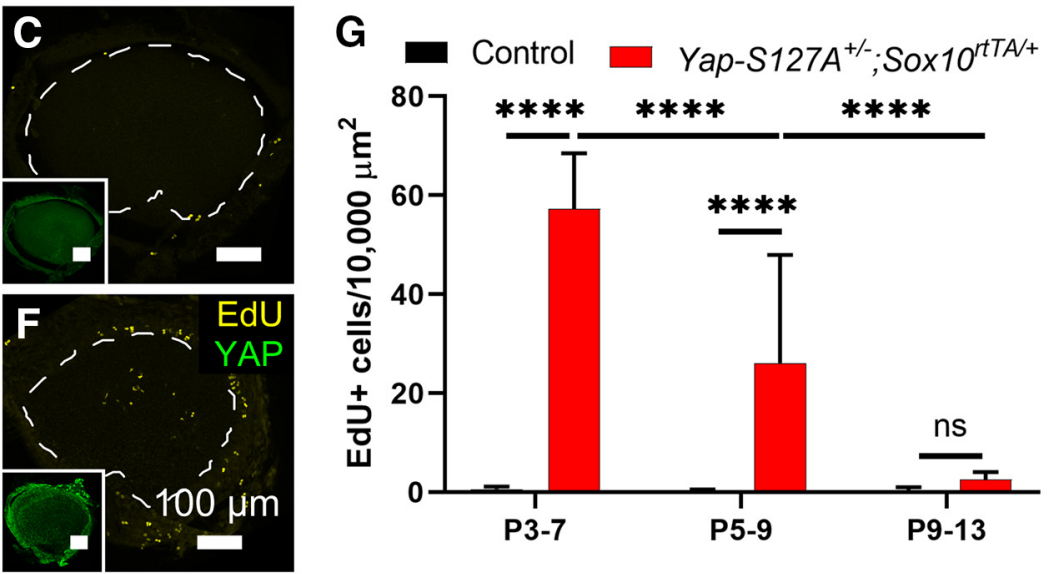
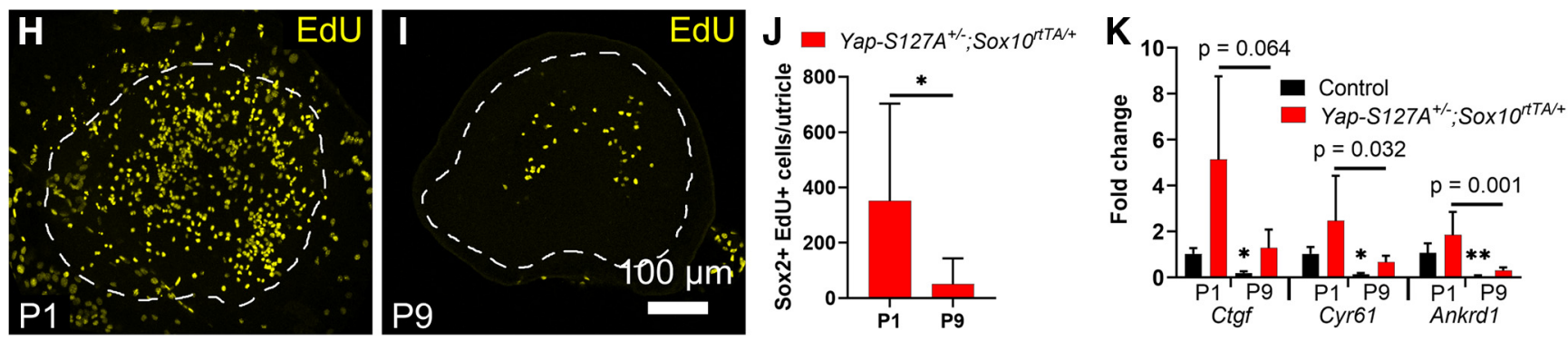

Figure 6. S-phase entry evoked by overexpression of YAP-S127A in the utricle declined during postnatal maturation. $\boldsymbol{A}-\boldsymbol{F}$, Low-magnification images of EdU showing that the S-phase entry in utricles of Yap-S127A ${ }^{+/-} ;$Sox $10^{r t T A+}$ mice $(\boldsymbol{D}-\boldsymbol{F})$ declined in an age-dependent fashion. Utricles from WT, Sox $10^{r t T A+}$, and Yap-S127A ${ }^{+/-}$littermates were used as controls. Insets, YAP immunoreactivity in age-matched utricles. G, Quantification of EdU ${ }^{+}$cell density revealed an age-dependent decrease in S-phase entry. A two-way ANOVA showed significant effects for genotype, age, and the age-genotype interaction (all $p<0.0001, n=6-16$ mice per condition). ${ }^{* * *} p<0.0001$ (Sidak's multiple comparisons tests). ns, Not significant ( $p>0.05$ ). $\boldsymbol{H}$, I, Low magnification images of explanted utricles from P1 and P9 Yap-S127A ${ }^{+/} ;$;ox $10^{\text {tTA/+ }}$ mice that were cultured in the presence of $10 \mu \mathrm{g} / \mathrm{ml}$ doxycycline and EdU for $72 \mathrm{~h}$. Dashed lines indicate the macular border as delineated by Sox2 immunostaining. J, Quantification of Sox2 ${ }^{+}$EdU $^{+}$cells revealed that the incidence of S-phase entry was significantly lower in utricles from P9 Yap$S 127 A^{+/-} ;$Sox $10^{r t T A /+}$ mice compared with P1 mice of that genotype ( $p=0.0277, n=6-9$ utricles). $K$, qRT-PCR revealed that expression of YAP-TEAD target genes relative to Gapdh declined in an age-related manner independent of genotype. Comparisons to P1 controls are indicated as follows: ${ }^{*} p=0.016 ;{ }^{* *} p=0.0095$; Mann-Whitney test. $n=4-6$ biological replicates. Data are mean \pm SD.

mice we generated developed tumors, even in the absence of tamoxifen administration. For this, we explanted utricles of Lats $1^{\text {flox/flox }}$; Lats $2^{\text {flox/flox }}$ mice and adenovirally transduced their SCs with mCherry or mCherry-T2A-Cre (LATS1/2 cKO). Utricles were cultured for $7 \mathrm{~d}$, with EdU added for the final $2 \mathrm{~d}$ to label SCs that entered S-phase. In utricles from P30 mice, phospho-YAP (S127) immunoreactivity was reduced in SCs of Lats $1^{\text {flox/flox }}$;Lats $2^{\text {flox/flox }}$ utricles that were transduced with mCherry-T2A-Cre compared with neighboring nontransduced SCs and SCs transduced with mCherry alone (Fig. 10C,D), indicating that LATS1/2 are expressed in mature SCs and mediate the continuous inhibitory phosphorylation of YAP.

Utricles from P1 Lats $1^{\text {flox flox }}$;Lats $2^{\text {flox/flox }}$ mice that were transduced with mCherry-T2A-Cre averaged 38-fold more EdU ${ }^{+}$SCs than controls $\left(240 \pm 145\right.$ vs $6 \pm 3, p=0.018, t_{(6)}=3.2, n=4$; Fig.

$\leftarrow$

$(p=0.033)$ and $\mathrm{SC}$ density $(p=0.008)$ were each significantly increased in utricles from Yap-S127A ${ }^{+/} ;$;ox $10^{\text {ttTA/+ }}$ mice compared with littermate controls ( $t$ test, $n=5-7$ mice). HC density did not significantly differ between utricles of Yap-S127A ${ }^{+/ /} ;$Sox $10^{\text {tTTA/+ }}$ mice and controls ( $p=0.36, t$ test, $n=5-7$ mice). $\mathbf{G}, \boldsymbol{H}$, Immunostaining of the apical junction marker 20-1 and the HC marker Myo7a in the lateral extrastriolar region of the utricle. Cells from the Yap-S127A ${ }^{+/} ;$Sox $10^{r t T A /+}$ mouse utricle $(\boldsymbol{H})$ are more densely packed and have irregular apical domain shapes compared with littermate controls $(\boldsymbol{G})$. Data are mean $\pm S D$. ${ }^{*} p<$ $0.05,{ }^{* * *} p<0.001$.
$10 E-G$ ), with some $\mathrm{EdU}^{+}$nuclei visible as mitotic figures (Fig. $\left.10 \mathrm{~F}^{\prime \prime \prime}\right)$. In P30 utricles, deletion of LATS1/2 significantly increased S-phase entry, albeit to a lesser extent than in P1. After 7 DIV, LATS1/2 cKO utricles averaged $12 \pm 15 \mathrm{EdU}^{+}$cells, 4.4-fold more than P30 controls $\left(p=0.0342, t_{(28)}=2.73, n=15\right)$. Extending the culture duration to 11 days resulted in $17 \pm 21$ EdU $^{+}$cells in LATS1/2 cKO utricles, a 9-fold increase over controls $\left(p=0.0393, t_{(18)}=2.22, n=10\right.$; Fig. $\left.10 H-J\right)$. The density of transduced SCs was not significantly different between P1 and P30 utricles (P1: $62 \pm 15$; P30: $53 \pm 27 \mathrm{SCs} / 10,000 \mu \mathrm{m}^{2} ; p=0.60, t_{(5)}$ $=0.56, n=3$ or 4$)$. In both P1 and P30 LATS1/2 cKO utricles, proliferating SCs were located in a striolar distribution (Fig. 10E,F). Thus, LATS1/2 are required for maintaining quiescence in a major subset of mature mammalian SCs.

\section{Discussion}

An emerging paradigm in epithelial repair specifies that upon damage, YAP accumulates in nuclei of stretched cells, where it promotes proliferation with TEAD transcription factors (Guillot and Lecuit, 2013; Benham-Pyle et al., 2015; Irvine and Shraiman, 2017). We found that YAP readily accumulated in SC nuclei of the chicken utricle in response to ototoxic and mechanical insult, but congruent with species differences in regenerative proliferation, YAP localization was less sensitive to shape change and acute inhibition of MST1/2 in murine SCs than in chicken 
Tead1
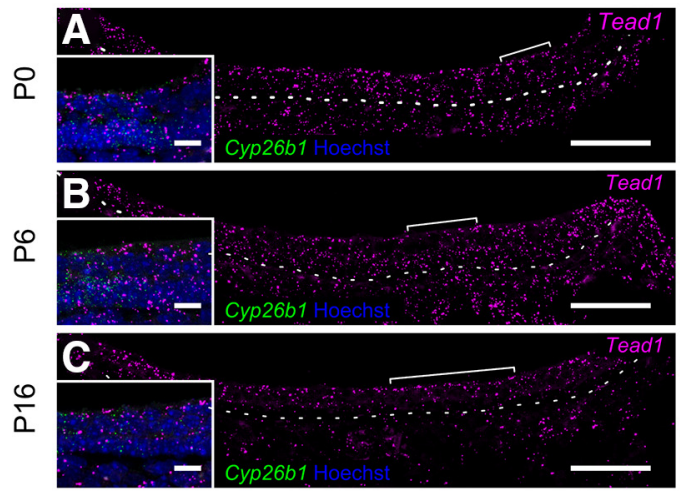

Mouse Utricle
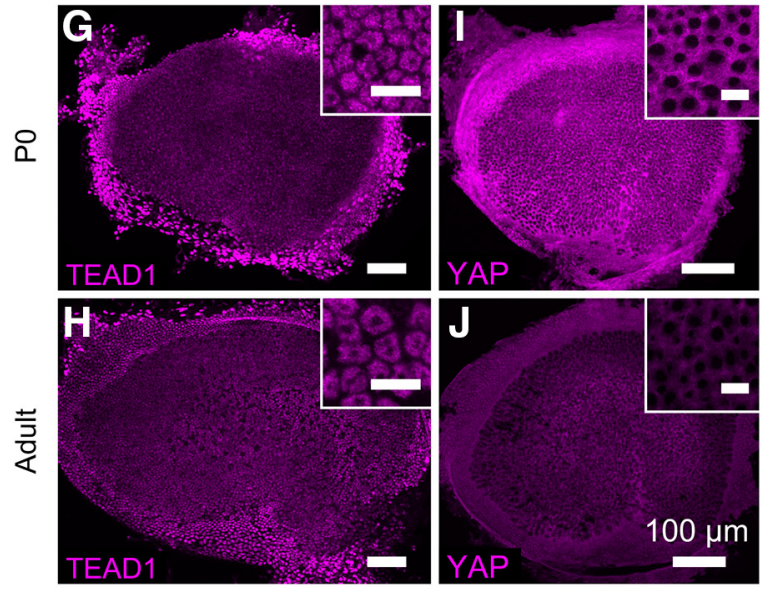

Tead2
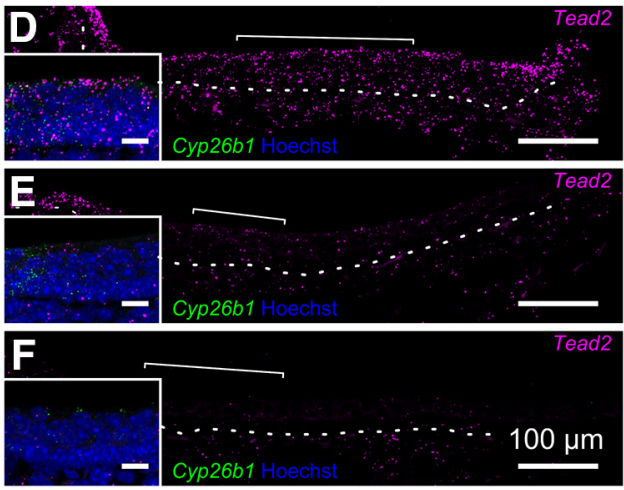

Adult Human Utricle

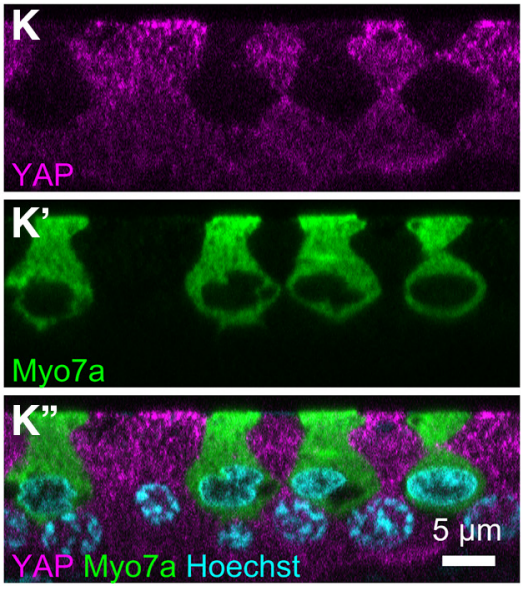

Figure 7. TEAD2 was downregulated as mice aged, but expression levels of TEAD1 and YAP were maintained throughout the utricle. A-F, Utricles of P0, P6, and P16 mice were fixed, frozen, sectioned, and probed for mRNA using RNAscope. TEAD1 message was detected throughout the utricle at all ages tested (A-C). TEAD2 message was detected throughout the utricle at P0 but declined in an age-dependent manner (D-F). Scale bars, $100 \mu \mathrm{m}$. White brackets represent the Cyp26b1 ${ }^{+}$striolar domain. Dashed lines indicate the border between the sensory epithelium and underlying stroma. Insets, Higher-magnification. Scale bars, $10 \mu \mathrm{m}$. G-J, TEAD1 and YAP antibody labeling in mouse utricles showed broad expression that persisted from newborn (G,I) to adult $(\boldsymbol{H}, \boldsymbol{S})$ stages. Insets, High-magnification images of the $\mathbf{S C}$ nuclear layer $(\boldsymbol{G}, \boldsymbol{H})$ and apical surface $(\boldsymbol{I}, \boldsymbol{S})$. Scale bars, $10 \mu \mathrm{m}$. $\boldsymbol{K}$, Orthogonal view of an adult human utricle immunostained for YAP and Myo7a with Hoechst labeling of cell nuclei.

SCs. Overexpressing a YAP-S127A variant, which could enter nuclei, elicited YAP-TEAD transcriptional activity and SC proliferation in the neonatal mouse utricle. This proliferative response declined with age but persisted to an extent in mature SCs. Ectopic WT YAP was phosphorylated and sequestered in the cytoplasm, but a YAP-5SA variant, which lacks LATS1/2 phosphorylation sites, entered nuclei of mature SCs and drove TEAD-dependent proliferation in the striola. Corroborating the importance of inhibitory phosphorylation, deletion of LATS1/2 reduced phospho-YAP and evoked proliferation of striolar SCs, even in adult mouse utricles. The results indicate that constitutive signaling by LATS1/2 kinases is required to phosphorylate YAP and hold SCs in mouse utricles in a persistent state of quiescence. The inhibitory Hippo pathway is active in SCs of the undamaged chicken utricle but is inactivated or bypassed upon $\mathrm{HC}$ loss. Overall, these findings provide a novel mechanistic basis to explain why mammals and nonmammals differ in their ability to replace sensory $\mathrm{HCs}$, and demonstrate that reactivation of YAP-TEAD signaling can be sufficient to induce SC proliferation in the mammalian balance epithelium.

The exact mechanism by which HC loss leads to the activation of YAP in chicken SCs remains to be elucidated. In chickens, HC loss results in rapid expansion of neighboring SC surfaces (Cotanche, 1987), and we found that shape changes correlated to the degree of YAP nuclear accumulation (Fig. 2). These shape changes may disrupt the MST1/2-LATS1/2 kinase cascade, allowing YAP to accumulate in the nucleus. Shape changes appear to modulate MST1/2 in certain epithelia (Varelas et al., 2010; Fletcher et al., 2018) but not others (Kim et al., 2011; Codelia et al., 2014; Meng et al., 2015), and some forms of mechanical regulation of YAP require neither MST1/2 nor LATS1/2 (Dupont et al., 2011; Aragona et al., 2013). As cell junctions strongly regulate Hippo signaling (Karaman and Halder, 2018), HC loss may induce nuclear accumulation of YAP in the SCs of fish and amphibians, whose junctions are similar to avian SCs in that they contain little E-cadherin and have thin circumferential F-actin bands (Burns et al., 2008, 2013).

Streptomycin-induced HC loss did not affect YAP localization in murine SCs (Fig. 1). Murine SCs must undergo larger shape changes than their avian counterparts in order to increase their likelihood of entering S-phase (Collado et al., 2011a). This corresponds to our observation that SC deformations induce nuclear accumulation of YAP in mammalian SCs, but to a lesser degree than in chicken SCs (Fig. 2). Thus, the shape changes produced by $\mathrm{HC}$ loss in the murine utricle may be below the threshold to evoke the nuclear accumulation of YAP, and additional inhibitory signals may restrict nuclear access of YAP.

In contrast to chicken SCs, acute MST1/2 inhibition did not affect YAP localization in murine SCs (Fig. 3). This suggests that MST1/2-independent mechanisms may activate LATS1/2 in 

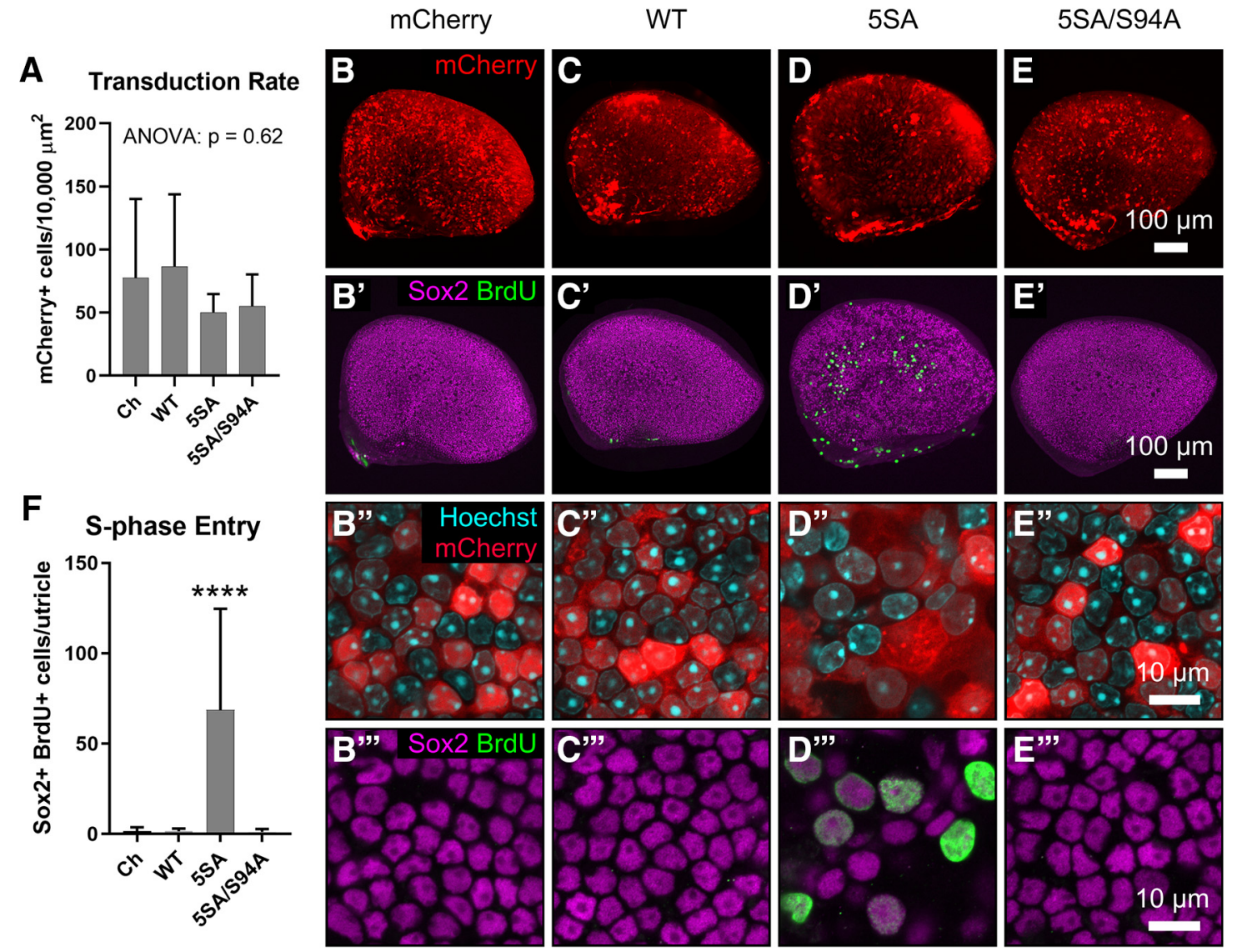

WT

$5 S A$
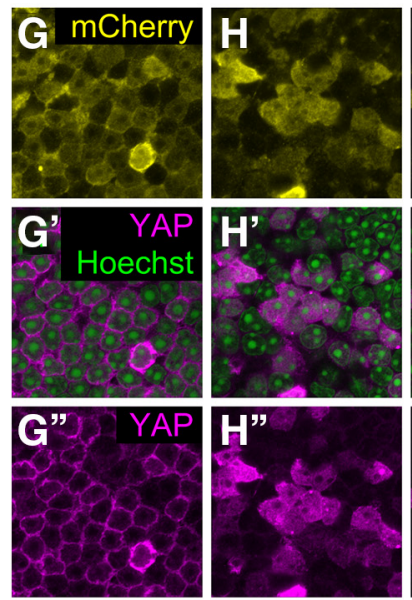
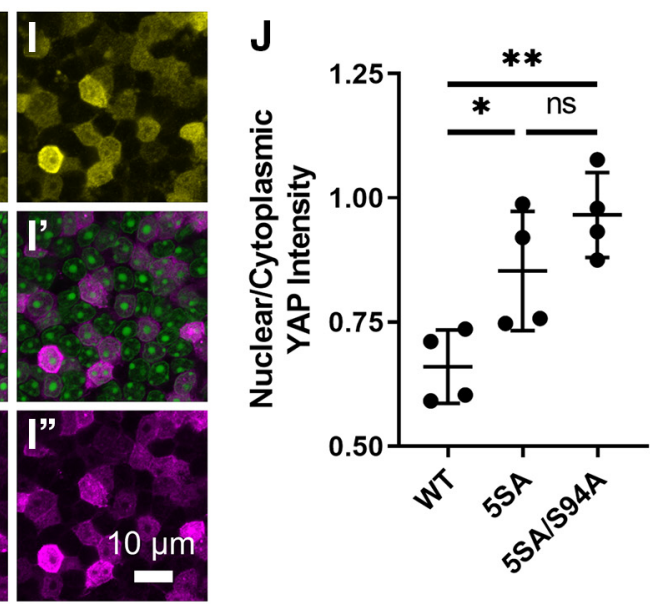

WT
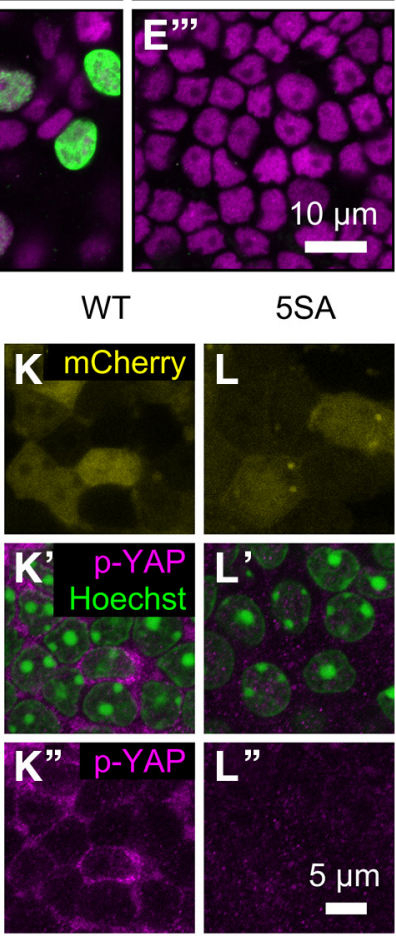

5SA

Figure 8. YAP-5SA entered SC nuclei and stimulated TEAD-dependent proliferation in P30 mouse utricles in vitro. Utricles of P30 mice were placed in culture and allowed to acclimate overnight. The following day, Type 5 adenovirus was used to transduce SCs with mCherry, WT YAP, YAP-5SA, or YAP-5SA/S94A. Utricles were maintained in the presence of BrdU for an additional $3 \mathrm{~d}$ before processing for immunohistochemistry. $\boldsymbol{A}$, Quantification revealed no significant differences in the transduction rates of the viruses $(p=0.62$, ANOVA, $n=4$ utricles). $\boldsymbol{B}-\boldsymbol{E}$, Low magnification images showed that transduction occurred in all conditions, but S-phase entry occurred exclusively in utricles that were transduced with YAP-5SA $\left(\boldsymbol{B}^{\prime}-\boldsymbol{E}^{\prime}\right)$. High-power images of the SC nuclear layer showing expression of the mCherry reporter $\left(\boldsymbol{B}^{\prime \prime}-\boldsymbol{E}^{\prime \prime}\right)$ as well as Sox2 and BrdU $\left(\boldsymbol{B}^{\prime \prime \prime}-\boldsymbol{E}^{\prime \prime \prime}\right)$. The BrdU ${ }^{+}$nuclei in utricles transduced with YAP-5SA colabeled with the SC marker

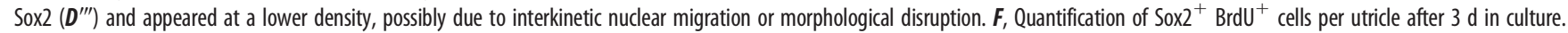
S-phase entry increased significantly in YAP-5SA-treated utricles ( $p<0.0001$, ANOVA, $n=10-16$ utricles). $\boldsymbol{G}, \boldsymbol{H}$, High-magnification images of the SC nuclear layer of utricles transduced with WT YAP, YAP-5SA, and YAP-5SA/S94A and analyzed $72 \mathrm{~h}$ after transduction. WT YAP was relatively enriched in cytoplasmic space surrounding SC nuclei $\left(\boldsymbol{G}^{\prime \prime}\right)$, whereas YAP-5SA and YAP-5SA/ S94A were relatively enriched in the SC nuclei $\left(H^{\prime \prime}, I^{\prime \prime}\right)$. $J$, The average YAP N:C ratio in utricles transduced with WT YAP $(0.66 \pm 0.07$, mean \pm SD) was significantly lower than those transduced with YAP-5SA $(0.85 \pm 0.12, p=0.0446)$ or YAP-5SA/S94A (0.97 $\pm 0.09, p=0.0036$, ANOVA with Tukey's multiple comparisons, $n=4$ utricles). $\boldsymbol{K}, \boldsymbol{L}$, High-magnification images of the SC nuclear layer of P30 mouse utricles transduced with WT YAP and analyzed $72 \mathrm{~h}$ after transduction. Cells positive for the mCherry reporter also were labeled by an antibody specific for YAP that is phosphorylated at serine $127(\boldsymbol{K})$. SCs transduced with YAP-5SA, which has a serine-to-alanine mutation at serine 127, served as a negative control for antibody specificity (L). Data are mean \pm SD. ns $p>0.05,{ }^{*} p<0.05,{ }^{* *} p<0.01,{ }^{* * *} p<0.001,{ }^{* * * *} p<0.0001$. 

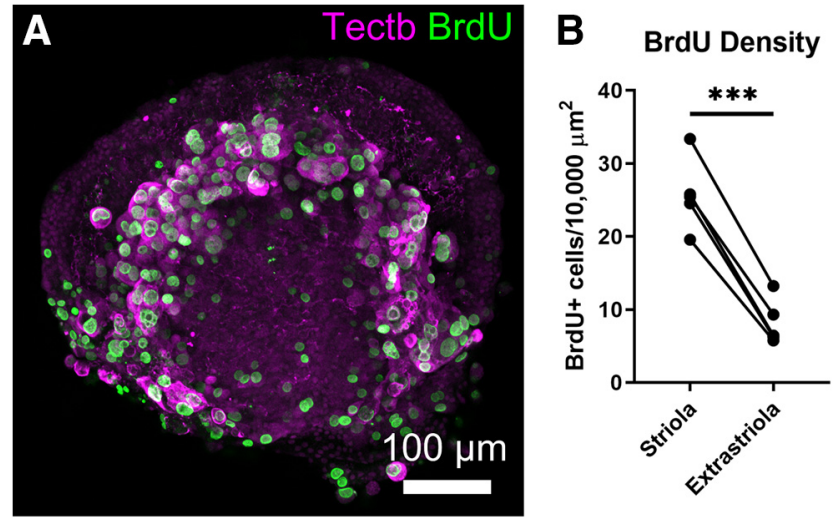

Figure 9. Cell cycle reentry evoked by YAP-5SA occurred selectively in striolar SCs. Utricles from P30 mice were transduced with YAP-5SA after an overnight acclimation period and cultured for an additional $5 \mathrm{~d}$ with BrdU prior to processing for immunohistochemistry. $A$, The majority of S-phase entry occurred in the $\mathrm{Tectb}^{+}$striolar region. $\boldsymbol{B}$, Quantification of BrdU ${ }^{+}$ cell density showed that proliferating cells were significantly more numerous in the Tectb ${ }^{+}$ striolar region than in the extrastriola ( $p=0.0001$, paired $t$ test, $n=5$ utricles). Graph represents individual values from each utricle. ${ }^{* * *} p<0.001$.

murine SCs. E-cadherin is reported to activate LATS1/2 independently of MST1/2 in other epithelia (Kim et al., 2011) and is expressed at much higher levels in mammalian SCs than in those of birds, fish, and amphibians (Collado et al., 2011b; Burns et al., 2013). Pharmacologic treatments that deplete E-cadherin from striolar SC junctions also affect YAP expression and induce SC proliferation (Kozlowski et al., 2020). Here, overexpression of YAP-S127A in mammalian SCs induced upregulation of E-cadherin in what may reflect negative feedback (Fig. 5A-D). MAP4K kinases and metabolic changes can also activate LATS1/ 2 independent of MST1/2 (Meng et al., 2015; Wang et al., 2015b; Nokin et al., 2016). Pinpointing which upstream signals activate LATS1/2 in mammalian SCs will aid efforts to overcome proliferative quiescence.

As the deletion of LATS1/2 reduced inhibitory phosphorylation of YAP and recapitulated the pattern of TEAD-dependent, striolar proliferation evoked by YAP-5SA overexpression, our data strongly suggest that LATS1/2 maintain proliferative quiescence by restricting YAP-TEAD signaling. Corroborating that notion, a recent report showed that pharmacologic inhibition of LATS1/2 kinase activity evokes YAP-dependent proliferation in mature mouse utricles (Kastan et al., 2020). However, these data do not exclude a contribution from YAP-independent mechanisms downstream of LATS1/2 inactivation, such as disassembly of the repressive DREAM complex (Tschöp et al., 2011).

LATS1 and LATS2 have overlapping functions and most prominently differ in their expression profiles (Furth and Aylon, 2017). These results do not distinguish whether one or both kinases is required to maintain SC quiescence. Likewise, YAP and its paralog TAZ have largely overlapping functions (Plouffe et al., 2018). Although we examined the localization and phosphorylation of YAP, damage and LATS1/2 deletion could similarly affect TAZ.

Overexpression of YAP-S127A is sufficient to stimulate widespread proliferation and increase cell density in the P1 mouse utricle (Figs. 4, 5), consistent with a model in which cell-densitydependent inactivation of YAP-TEAD signaling mediates cell cycle arrest in the developing utricle (Gnedeva et al., 2017). However, since cell density in the murine utricle plateaus around E17.5 (Gnedeva et al., 2017), the model does not account for postnatal declines in the capacity of SCs to overcome proliferative quiescence (Burns et al., 2012a). Since this age-dependent decline occurs despite overexpression of YAP-S127A or deletion of LATS1/2, the data indicate that SC proliferation is further restricted by age-dependent changes that lie downstream of YAP inhibitory phosphorylation, such as the downregulation of TEAD2 or changes in parallel pathways, such as canonical Wnt signaling, Notch signaling, Atoh1 expression, and SoxC expression (Gnedeva and Hudspeth, 2015; Maass et al., 2015; Wang et al., 2015a; Samarajeewa et al., 2018; Sayyid et al., 2019).

It appears that multiple layers of regulation contribute to SC quiescence, albeit not equally across all HC epithelia. For example, chromatin is less accessible in cochlear SCs than utricular SCs (Jen et al., 2019), and striolar SCs were more likely to proliferate than extrastriolar SCs when inhibitory phosphorylation of YAP was bypassed (Figs. 6, 8-10). The proliferation rates of striolar and extrastriolar SCs varied slightly between in vivo and in vitro experiments (Figs. $4 F, 6$ ), possibly due to doxycycline bioavailability or culture conditions. The progressive restriction of S-phase entry to the striolar region of the utricle after YAPS127A overexpression in vivo and in vitro (Fig. 6) suggests that striolar-extrastriolar differences widen throughout postnatal maturation. The low rate of extrastriolar proliferation in P1 LATS1/2 cKO utricles may be due to aging of the explant during the processes of adenoviral transduction, Cre expression, recombination of LATS1/2 alleles, and degradation of preexisting LATS1/2 mRNA and protein (Fig. $10 E-G$ ). YAP was no more likely to accumulate in nuclei of striolar SCs than in extrastriolar SCs after streptomycin damage (Fig. 1) or MST1/2 inhibition (Fig. 3), suggesting that factors downstream of YAP nuclear accumulation or in parallel pathways account for the different responsiveness. Although expression of TEAD1 and TEAD2 did not appear to differ between striolar and extrastriolar SCs (Fig. 7), their transcriptional activity may be uniquely restricted in extrastriolar SCs (Chang et al., 2018). Additionally, extrastriolar SCs may lack signals that promote proliferation downstream of YAP-TEAD signaling: Wnt is reported to control proliferation downstream of YAP in organoids derived from cochlear progenitors that express $\operatorname{Lgr}^{+}$(Xia et al., 2020), and striolar SCs, which express $\operatorname{Lgr} 5^{+}$are more responsive to Wnt than extrastriolar SCs (Lin et al., 2015; Wang et al., 2015a; You et al., 2018). Retinoic acid receptor signaling is elevated in the developing extrastriola (Ono et al., 2020) and could limit proliferation there, consistent with its reported role in promoting cell cycle exit and differentiation in neural progenitors (Janesick et al., 2015).

Regenerative proliferation is essential to mitotically replace HCs and to replenish the pool of SCs after direct transdifferentiation. It has remained unclear why SCs in nonmammalian vertebrates readily proliferate following $\mathrm{HC}$ loss, and those in mammals do not (Forge et al., 1993; Warchol et al., 1993; Golub et al., 2012; Bucks et al., 2017; Senn et al., 2019). Our results uncover distinctions in the regulation of YAP, which may contribute to that difference. While YAP is required for regenerative proliferation in the chicken utricle, mammalian SCs appear to regulate YAP with a different mechanism that is thus far insensitive to $\mathrm{HC}$ loss and may be related to the postnatal reinforcement of intercellular junctions that occurs uniquely in mammalian SCs (Burns et al., 2008, 2013; Collado et al., 2011b). We find that the quiescence of SCs in mature mammals is maintained in part by the constitutive activity of LATS1/2 kinases that phosphorylate YAP and restrict its ability to regulate gene expression with TEAD. Approaches to inhibit LATS1/2 kinase activity eventually may be used to promote replacement of lost HCs for the treatment of hearing loss and balance disorders. 

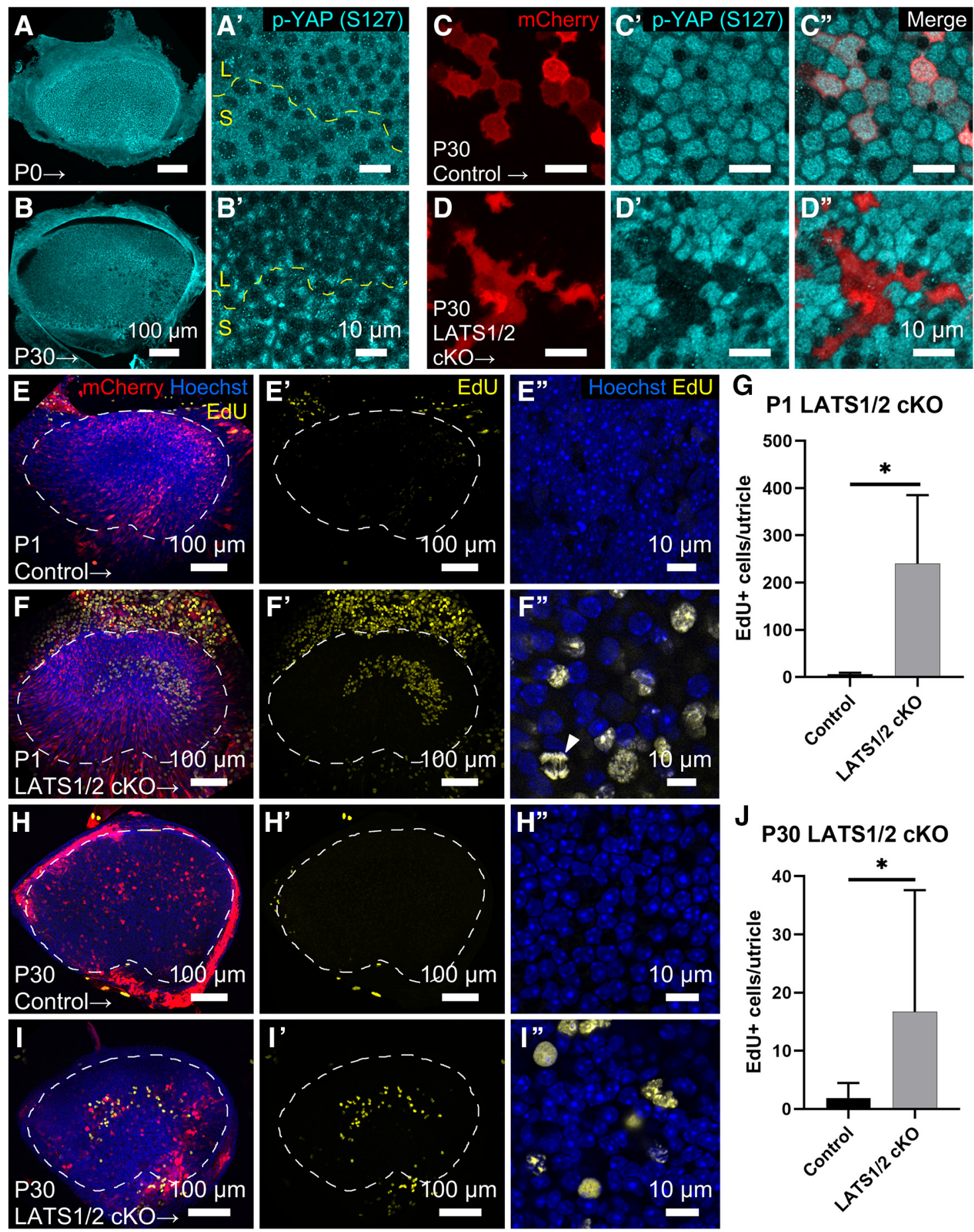

Figure 10. Deletion of LATS1 and LATS2 reduced the inhibitory phosphorylation of YAP and induced proliferation of SCS in utricles from neonatal and adult mice. $\boldsymbol{A}, \boldsymbol{B}$, Utricles of P0 and P30 mice were immunolabeled for phospho-YAP (S127), a measure of LATS1/2 kinase activity. Phospho-YAP immunoreactivity was detectable in SCs within the striolar and lateral regions both at P0 and at P30. Dashed yellow line indicates the line of polarity reversal, which separates the lateral extrastriolar and striolar regions. C, D, High-magnification image of the apical surface of

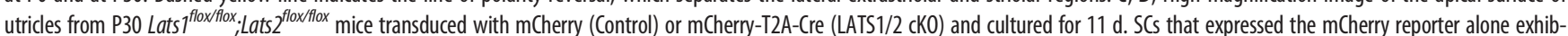
ited similar levels of phospho-YAP (S127) immunoreactivity compared with neighboring SCs that were not transduced (C). Levels of phospho-YAP (S127) were lower in SCs that expressed Cre, suggesting that deletion of LATS1 and LATS2 occurred (D). E, F, Utricles were explanted from Lats $7^{\text {floxflox }}$;Lats2 ${ }^{\text {flox flox }}$ mice at P1 and transduced with mCherry (control) or mCherry-T2A-Cre (LATS1/2 CKO) and cultured for $7 \mathrm{~d}$. EdU was added for the final $2 \mathrm{~d}$ of culture to trace cells that entered S-phase. Few EdU ${ }^{+}$cells were present in control utricles $\left(\boldsymbol{E}, \boldsymbol{E}^{\prime}\right)$, but substantial numbers were found in the central region of LATS1/2 cK0 utricles $\left(\boldsymbol{F}, \boldsymbol{F}^{\prime}\right)$. High-magnification images of the SC layer $\left(\boldsymbol{E}^{\prime \prime}, \boldsymbol{F}^{\prime \prime}\right)$ show EdU ${ }^{+}$nuclei and a mitotic figure (arrowhead) in a LATS1/2 cKO utricle $\left(\boldsymbol{F}^{\prime \prime}\right)$. G, Quantification of EdU ${ }^{+}$cells in P1 control and LATS1/2 cKO utricles shows that LATS1/2 cKO significantly increased S-phase entry over controls $(p=0.018, n=4$ utricles). $\boldsymbol{H}, \boldsymbol{I}$,

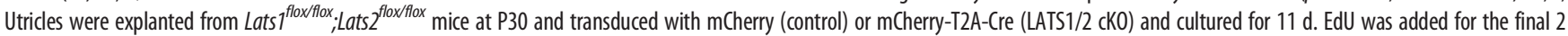
$\mathrm{d}$ of culture. Control utricles contained few EdU ${ }^{+}$cells $\left(\boldsymbol{H}, \boldsymbol{H}^{\prime}\right)$, and significantly more EdU ${ }^{+}$cells were observed in a striolar distribution of LATS1/2 cKO utricles $\left(\boldsymbol{I}, \boldsymbol{I}^{\prime}\right)$. $\boldsymbol{J}$, Quantification shows significantly increased EdU ${ }^{+}$cell counts in P30 LATS1/2 cK0 utricles compared with controls ( $p=0.0393, n=10$ utricles). Dashed lines indicate the boundary of the macula. Data are mean \pm SD. ${ }^{*} p<0.05$. 


\section{References}

Adler HJ, Raphael Y (1996) New hair cells arise from supporting cell conversion in the acoustically damaged chick inner ear. Neurosci Lett 205:1720.

Agrawal Y, Carey JP, Della Santina CC, Schubert MC, Minor LB (2009) Disorders of balance and vestibular function in US adults: data from the National Health and Nutrition Examination Survey, 2001-2004. Arch Intern Med 169:938.

Aragona M, Panciera T, Manfrin A, Giulitti S, Michielin F, Elvassore N, Dupont S, Piccolo S (2013) A mechanical checkpoint controls multicellular growth through YAP/TAZ regulation by actin-processing factors. Cell 154:1047-1059.

Atkinson PJ, Dong Y, Gu S, Liu W, Najarro EH, Udagawa T, Cheng AG (2018) Sox2 haploinsufficiency primes regeneration and Wnt responsiveness in the mouse cochlea. J Clin Invest 128:1641-1656.

Baird RA, Steyger PS, Schuff NR (1996) Mitotic and nonmitotic hair cell regeneration in the bullfrog vestibular otolith organsa. Ann NY Acad Sci 781:59-70.

Balak KJ, Corwin JT, Jones JE (1990) Regenerated hair cells can originate from supporting cell progeny: evidence from phototoxicity and laser ablation experiments in the lateral line system. J Neurosci 10:2502-2512.

Basu S, Totty NF, Irwin MS, Sudol M, Downward J (2003) Akt phosphorylates the Yes-associated protein, YAP, to induce interaction with 14-3-3 and attenuation of p73-mediated apoptosis. Mol Cell 11:11-23.

Benham-Pyle BW, Pruitt BL, Nelson WJ (2015) Mechanical strain induces Ecadherin-dependent Yap1 and $\beta$-catenin activation to drive cell cycle entry. Science 348:1024-1027.

Bucks SA, Cox BC, Vlosich BA, Manning JP, Nguyen TB, Stone JS (2017) Supporting cells remove and replace sensory receptor hair cells in a balance organ of adult mice. eLife 6:e18128.

Burns J, Christophel JJ, Collado MS, Magnus C, Carfrae M, Corwin JT (2008) Reinforcement of cell junctions correlates with the absence of hair cell regeneration in mammals and its occurrence in birds. J Comp Neurol 511:396-414.

Burns JC, Collado MS, Oliver ER, Corwin JT (2013) Specializations of intercellular junctions are associated with the presence and absence of hair cell regeneration in ears from six vertebrate classes. J Comp Neurol 521:1430-1448.

Burns JC, Cox BC, Thiede BR, Zuo J, Corwin JT (2012a) In vivo proliferative regeneration of balance hair cells in newborn mice. J Neurosci 32:65706577.

Burns JC, On D, Baker W, Collado MS, Corwin JT (2012b) Over half the hair cells in the mouse utricle first appear after birth, with significant numbers originating from early postnatal mitotic production in peripheral and striolar growth zones. J Assoc Res Otolaryngol 13:609-627.

Burns JC, Yoo JJ, Atala A, Jackson JD (2012c) MYC gene delivery to adult mouse utricles stimulates proliferation of postmitotic supporting cells in vitro. PLoS One 7:e48704.

Camargo FD, Gokhale S, Johnnidis JB, Fu D, Bell GW, Jaenisch R, Brummelkamp TR (2007) YAP1 increases organ size and expands undifferentiated progenitor cells. Curr Biol 17:2054-2060.

Chang L, Azzolin L, Biagio DD, Zanconato F, Battilana G, Xiccato RL, Aragona M, Giulitti S, Panciera T, Gandin A, Sigismondo G, Krijgsveld J, Fassan M, Brusatin G, Cordenonsi M, Piccolo S (2018) The SWI/SNF complex is a mechanoregulated inhibitor of YAP and TAZ. Nature 563:265.

Codelia VA, Sun G, Irvine KD (2014) Regulation of YAP by mechanical strain through Jnk and Hippo signaling. Curr Biol 24:2012-2017.

Collado MS, Burns JC, Meyers JR, Corwin JT (2011a) Variations in shapesensitive restriction points mirror differences in the regeneration capacities of avian and mammalian ears. PLoS One 6:e23861.

Collado MS, Thiede BR, Baker W, Askew C, Igbani LM, Corwin JT (2011b) The postnatal accumulation of junctional E-cadherin is inversely correlated with the capacity for supporting cells to convert directly into sensory hair cells in mammalian balance organs. J Neurosci 31:11855-11866.

Corwin JT, Cotanche DA (1988) Regeneration of sensory hair cells after acoustic trauma. Science 240:1772-1774.

Cotanche DA (1987) Regeneration of hair cell stereociliary bundles in the chick cochlea following severe acoustic trauma. Hear Res 30:181-195.

Cox BC, Chai R, Lenoir A, Liu Z, Zhang L, Nguyen DH, Chalasani K, Steigelman KA, Fang J, Cheng AG, Zuo J (2014) Spontaneous hair cell regeneration in the neonatal mouse cochlea in vivo. Development 141:816-829.

Dai X, Liu H, Shen S, Guo X, Yan H, Ji X, Li L, Huang J, Feng XH, Zhao B (2015) YAP activates the Hippo pathway in a negative feedback loop. Cell Res 25:1175-1178.

Davies D, Magnus C, Corwin JT (2007) Developmental changes in cellextracellular matrix interactions limit proliferation in the mammalian inner ear. Eur J Neurosci 25:985-998.

Doerflinger NH, Macklin WB, Popko B (2003) Inducible site-specific recombination in myelinating cells. Genesis 35:63-72.

Dong J, Feldmann G, Huang J, Wu S, Zhang N, Comerford SA, Gayyed MF, Anders RA, Maitra A, Pan D (2007) Elucidation of a universal size-control mechanism in Drosophila and mammals. Cell 130:1120.

Dupont S, Morsut L, Aragona M, Enzo E, Giulitti S, Cordenonsi M, Zanconato F, Le Digabel J, Forcato M, Bicciato S, Elvassore N, Piccolo S (2011) Role of YAP/TAZ in mechanotransduction. Nature 474:179-183.

Fan F, He Z, Kong L, Chen Q, Yuan Q, Zhang S, Ye J, Liu H, Sun X, Geng J, Yuan L, Hong L, Xiao C, Zhang W, Sun X, Li Y, Wang P, Huang L, Wu X, Ji Z, et al. (2016) Pharmacological targeting of kinases MST1 and MST2 augments tissue repair and regeneration. Sci Transl Med 8:352ra1088.

Fletcher GC, Diaz-de-la-Loza MC, Borreguero-Muñoz N, Holder M, Aguilar-Aragon M, Thompson BJ (2018) Mechanical strain regulates the Hippo pathway in Drosophila. Development 145:dev159467.

Forge A, Li L, Corwin JT, Nevill G (1993) Ultrastructural evidence for hair cell regeneration in the mammalian inner ear. Science 259:1616-1619.

Furth N, Aylon Y (2017) The LATS1 and LATS2 tumor suppressors: beyond the Hippo pathway. Cell Death Differ 24:1488-1501.

Gnedeva K, Hudspeth AJ (2015) SoxC transcription factors are essential for the development of the inner ear. Proc Natl Acad Sci USA 112:1406614071.

Gnedeva K, Jacobo A, Salvi JD, Petelski AA, Hudspeth AJ (2017) Elastic force restricts growth of the murine utricle. eLife $6: \mathrm{e} 25681$.

Golub JS, Tong L, Ngyuen TB, Hume CR, Palmiter RD, Rubel EW, Stone JS (2012) Hair cell replacement in adult mouse utricles after targeted ablation of hair cells with diphtheria toxin. J Neurosci 32:15093-15105.

Gu R, Montcouquiol M, Marchionni M, Corwin JT (2007) Proliferative responses to growth factors decline rapidly during postnatal maturation of mammalian hair cell epithelia. Eur J Neurosci 25:1363-1372.

Guillot C, Lecuit T (2013) Mechanics of epithelial tissue homeostasis and morphogenesis. Science 340:1185-1189.

Harris JA, Cheng AG, Cunningham LL, MacDonald G, Raible DW, Rubel EW (2003) Neomycin-induced hair cell death and rapid regeneration in the lateral line of zebrafish (Danio rerio). J Assoc Res Otolaryngol 4:219234.

Heallen T, Morikawa Y, Leach J, Tao G, Willerson JT, Johnson RL, Martin JF (2013) Hippo signaling impedes adult heart regeneration. Dev Camb Engl 140:4683-4690.

Irvine KD, Shraiman BI (2017) Mechanical control of growth: ideas, facts and challenges. Development 144:4238-4248.

Janesick A, Wu SC, Blumberg B (2015) Retinoic acid signaling and neuronal differentiation. Cell Mol Life Sci 72:1559-1576.

Jen HI, Hill MC, Tao L, Sheng K, Cao W, Zhang H, Yu HV, Llamas J, Zong C, Martin JF, Segil N, Groves AK (2019) Transcriptomic and epigenetic regulation of hair cell regeneration in the mouse utricle and its potentiation by Atoh1. eLife 8:e44328.

Jones JE, Corwin JT (1996) Regeneration of sensory cells after laser ablation in the lateral line system: hair cell lineage and macrophage behavior revealed by time-lapse video microscopy. J Neurosci 16:649-662.

Karaman R, Halder G (2018) Cell junctions in Hippo signaling. Cold Spring Harb Perspect Biol 10:a028753.

Kastan N, Gnedeva K, Alisch T, Petelski AA, Huggins DJ, Chiaravalli J, Aharanov A, Shakked A, Tzahor E, Nagiel A, Segil N, Hudspeth AJ (2020) Small-molecule inhibition of Lats kinases promotes Yap-dependent proliferation in postmitotic mammalian tissues. bioRxiv:2020.02.11. 944157.

Kim NG, Koh E, Chen X, Gumbiner BM (2011) E-cadherin mediates contact inhibition of proliferation through Hippo signaling-pathway components. Proc Natl Acad Sci USA 108:11930-11935.

Kozlowski MM, Rudolf MA, Corwin JT (2020) EGF and a GSK3 inhibitor deplete junctional E-cadherin and stimulate proliferation in the mature mammalian ear. J Neurosci 40:2618-2632. 
Lin J, Zhang X, Wu F, Lin W (2015) Hair cell damage recruited Lgr5-expressing cells are hair cell progenitors in neonatal mouse utricle. Front Cell Neurosci 9:113.

$\mathrm{Lu} \mathrm{Z,} \mathrm{Corwin} \mathrm{JT} \mathrm{(2008)} \mathrm{The} \mathrm{influence} \mathrm{of} \mathrm{glycogen} \mathrm{synthase} \mathrm{kinase} 3$ in limiting cell addition in the mammalian ear. Dev Neurobiol 68:1059-1075.

Ludwig A, Schlierf B, Schardt A, Nave KA, Wegner M (2004) Sox10-rtTA mouse line for tetracycline-inducible expression of transgenes in neural crest cells and oligodendrocytes. Genesis 40:171-175.

Luo W, Wang X, Ma R, Chi F, Chen P, Cong N, Gu Y, Ren D, Yang J (2018) Junctional E-cadherin/p120-catenin is correlated with the absence of supporting cells to hair cells conversion in postnatal mice cochleae. Front Mol Neurosci 11:20.

Lush ME, Piotrowski T (2014) Sensory hair cell regeneration in the zebrafish lateral line. Dev Dyn 243:1187-1202.

Maass JC, Gu R, Basch ML, Waldhaus J, Lopez EM, Xia A, Oghalai JS, Heller S, Groves AK (2015) Changes in the regulation of the Notch signaling pathway are temporally correlated with regenerative failure in the mouse cochlea. Front Cell Neurosci 9:110.

Meng Z, Moroishi T, Mottier-Pavie V, Plouffe SW, Hansen CG, Hong AW, Park HW, Mo JS, Lu W, Lu S, Flores F, Yu FX, Halder G, Guan KL (2015) MAP4K family kinases act in parallel to MST1/2 to activate LATS1/2 in the Hippo pathway. Nat Commun 6:8357.

Meyers JR, Corwin JT (2007) Shape change controls supporting cell proliferation in lesioned mammalian balance epithelium. J Neurosci 27:43134325.

Mizutari K, Fujioka M, Hosoya M, Bramhall N, Okano HJ, Okano H, Edge AS (2013) Notch inhibition induces cochlear hair cell regeneration and recovery of hearing after acoustic trauma. Neuron 77:58-69.

Moroishi T, Park HW, Qin B, Chen Q, Meng Z, Plouffe SW, Taniguchi K, Yu FX, Karin M, Pan D, Guan KL (2015) A YAP/TAZ-induced feedback mechanism regulates Hippo pathway homeostasis. Genes Dev 29:12711284.

Nadol JB (1993) Hearing loss. N Engl J Med 329:1092-1102.

Nokin MJ, Durieux F, Peixoto P, Chiavarina B, Peulen O, Blomme A, Turtoi A, Costanza B, Smargiasso N, Baiwir D, Scheijen JL, Schalwijk CG, Leenders J, De Tullio P, Bianchi E, Thiry M, Uchida K, Spiegel DA, Cochrane JR, Hutton CA, et al. (2016) Methylglyoxal, a glycolysis sideproduct, induces Hsp90 glycation and YAP-mediated tumor growth and metastasis. eLife 5:e19375.

Ono K, Keller J, López Ramírez O, González Garrido A, Zobeiri OA, Chang HH, Vijayakumar S, Ayiotis A, Duester G, Della Santina CC, Jones SM, Cullen KE, Eatock RA, Wu DK (2020) Retinoic acid degradation shapes zonal development of vestibular organs and sensitivity to transient linear accelerations. Nat Commun 11:63.

Park GS, Oh H, Kim M, Kim T, Johnson RL, Irvine KD, Lim DS (2016) An evolutionarily conserved negative feedback mechanism in the Hippo pathway reflects functional difference between LATS1 and LATS2. Oncotarget 7:24063-24075.

Plouffe SW, Lin KC, Moore JL, Tan FE, Ma S, Ye Z, Qiu Y, Ren B, Guan KL (2018) The Hippo pathway effector proteins YAP and TAZ have both distinct and overlapping functions in the cell. J Biol Chem 293:1123011240 .

Ryals BM, Rubel EW (1988) Hair cell regeneration after acoustic trauma in adult Coturnix quail. Science 240:1774-1776.

Samarajeewa A, Lenz DR, Xie L, Chiang H, Kirchner R, Mulvaney JF, Edge AS, Dabdoub A (2018) Transcriptional response to Wnt activation regulates the regenerative capacity of the mammalian cochlea. Development 145:dev166579.

Sayyid ZN, Wang T, Chen L, Jones SM, Cheng AG (2019) Atoh1 directs regeneration and functional recovery of the mature mouse vestibular system. Cell Rep 28:312-324.e4.

Schindelin J, Arganda-Carreras I, Frise E, Kaynig V, Longair M, Pietzsch T, Preibisch S, Rueden C, Saalfeld S, Schmid B, Tinevez JY, White DJ, Hartenstein V, Eliceiri K, Tomancak P, Cardona A (2012) Fiji: an opensource platform for biological-image analysis. Nat Methods 9:676-682.

Senn P, Mina A, Volkenstein S, Kranebitter V, Oshima K, Heller S (2019) Progenitor cells from the adult human inner ear. Anat Rec 303:461-470.
Shreberk-Shaked M, Oren M (2019) New insights into YAP/TAZ nucleocytoplasmic shuttling: new cancer therapeutic opportunities? Mol Oncol 13:1335-1341.

Smith ME, Coffin AB, Miller DL, Popper AN (2006) Anatomical and functional recovery of the goldfish (Carassius auratus) ear following noise exposure. J Exp Biol 209:4193-4202.

Smolders JW (1999) Functional recovery in the avian ear after hair cell regeneration. Audiol Neurootol 4:286-302.

Song S, Xie M, Scott AW, Jin J, Ma L, Dong X, Skinner HD, Johnson RL, Ding S, Ajani JA (2018) A novel YAP1 inhibitor targets CSC-enriched radiation-resistant cells and exerts strong antitumor activity in esophageal adenocarcinoma. Mol Cancer Ther 17:443-454.

Totaro A, Panciera T, Piccolo S (2018) YAP/TAZ upstream signals and downstream responses. Nat Cell Biol 20:888-899.

Tschöp K, Conery AR, Litovchick L, DeCaprio JA, Settleman J, Harlow E, Dyson N (2011) A kinase shRNA screen links LATS2 and the pRB tumor suppressor. Genes Dev 25:814-830.

Varelas X, Samavarchi-Tehrani P, Narimatsu M, Weiss A, Cockburn K, Larsen BG, Rossant J, Wrana JL (2010) The Crumbs complex couples cell density sensing to Hippo-dependent control of the TGF- $\beta$-SMAD pathway. Dev Cell 19:831-844.

Vassilev A, Kaneko KJ, Shu H, Zhao Y, DePamphilis ML (2001) TEAD/TEF transcription factors utilize the activation domain of YAP65, a Src/Yesassociated protein localized in the cytoplasm. Genes Dev 15:1229-1241.

Walters BJ, Zuo J (2015) A Sox10rtTA/+ mouse line allows for inducible gene expression in the auditory and balance organs of the inner ear. J Assoc Res Otolaryngol 16:331-345.

Wang T, Chai R, Kim GS, Pham N, Jansson L, Nguyen DH, Kuo B, May LA, Zuo J, Cunningham LL, Cheng AG (2015a) Lgr5+ cells regenerate hair cells via proliferation and direct transdifferentiation in damaged neonatal mouse utricle. Nat Commun 6:6613.

Wang W, Xiao ZD, Li X, Aziz KE, Gan B, Johnson RL, Chen J (2015b) AMPK modulates Hippo pathway activity to regulate energy homeostasis. Nat Cell Biol 17:490-499.

Warchol ME, Lambert PR, Goldstein BJ, Forge A, Corwin JT (1993) Regenerative proliferation in inner ear sensory epithelia from adult guinea pigs and humans. Science 259:1619-1622.

World Health Organization (2018) Global estimates on prevalence of hearing loss. Geneva: World Health Organization.

Xia M, Chen Y, He Y, Li H, Li W (2020) Activation of the RhoA-YAP- $\beta$-catenin signaling axis promotes the expansion of inner ear progenitor cells in 3D culture. Stem Cells. Advance online publication. Retrieved Mar 11, 2020. doi: $10.1002 /$ stem. 3175 .

Xin M, Kim Y, Sutherland LB, Murakami M, Qi X, McAnally J, Porrello ER, Mahmoud AI, Tan W, Shelton JM, Richardson JA, Sadek HA, BasselDuby R, Olson EN (2013) Hippo pathway effector Yap promotes cardiac regeneration. Proc Natl Acad Sci USA 110:13839-13844.

Xin M, Kim Y, Sutherland LB, Qi X, McAnally J, Schwartz RJ, Richardson JA, Bassel-Duby R, Olson EN (2011) Regulation of insulin-like growth factor signaling by Yap governs cardiomyocyte proliferation and embryonic heart size. Sci Signal 4:ra70.

You D, Guo L, Li W, Sun S, Chen Y, Chai R, Li H (2018) Characterization of Wnt and Notch-responsive Lgr5+ hair cell progenitors in the striolar region of the neonatal mouse utricle. Front Mol Neurosci 11:137.

Zhao B, Kim J, Ye X, Lai ZC, Guan KL (2009) Both TEAD-binding and WW domains are required for the growth stimulation and oncogenic transformation activity of Yes-associated protein. Cancer Res 69:1089-1098.

Zhao B, Li L, Tumaneng K, Wang CY, Guan KL (2010) A coordinated phosphorylation by Lats and CK1 regulates YAP stability through $\operatorname{SCF} \beta$ TRCP. Genes Dev 24:72-85.

Zhao B, Wei X, Li W, Udan RS, Yang Q, Kim J, Xie J, Ikenoue T, Yu J, Li L, Zheng P, Ye K, Chinnaiyan A, Halder G, Lai ZC, Guan KL (2007) Inactivation of YAP oncoprotein by the Hippo pathway is involved in cell contact inhibition and tissue growth control. Genes Dev 21:27472761.

Zhao B, Ye X, Yu J, Li L, Li W, Li S, Yu J, Lin JD, Wang CY, Chinnaiyan AM, Lai ZC, Guan KL (2008) TEAD mediates YAP-dependent gene induction and growth control. Genes Dev 22:1962-1971. 